\title{
Does ratification matter and do major conventions improve safety and decrease pollution in shipping?
}

\author{
Sabine Knapp ${ }^{1}$, Philip Hans Franses \\ Econometric Institute, Erasmus University Rotterdam ${ }^{2}$
}

Econometric Institute Report 2009-03

\begin{abstract}
We develop a method which measures the effect of the major international conventions in the area of safety, pollution, search and rescue and work related measures. We further distinguish between the effect of entry into force and the status of ratification of a convention by its parties. We use standard econometric models and base our analysis on a unique dataset of 30 years of monthly data where we correct for other factors which can influence safety such as safety inspections and ship economic cycles. The results show a complex picture where the average time between adoption and entry into force was calculated to be 3.1 years. Overall, the more parties ratify a convention, the more likely safety is improved and pollution is decreased although one can detect a certain level of non compliance. The immediate effect of entry into force presents a mixed picture where most negative effects can be found with legislation in the area of safety management and pollution, followed by technical areas. The effect of legislation in the areas related to working and living conditions and certification and training is smallest. Seasonality can be found with peaks in December and January for all conventions but are less important for pollution.
\end{abstract}

\section{Acknowledgments}

We would like to acknowledge Lloyd's Register Fairplay (LRF) for proving casualty and pollution data and the Paul Scherrer Institute (PSI) for providing oil pollution data. Furthermore we would like to thank Clarksons for providing data on ship economic cycles. Finally we would like to thank Mr. Gangcan Rao for his very helpful insight into the development of the legislative framework and the identification of milestones relevant for this analysis.

\footnotetext{
${ }^{1}$ Disclaimer: The views expressed in this article represent those of the author and do not necessarily represent those of the International Maritime Organization (IMO)

${ }^{2}$ Econometric Institute, Erasmus School of Economics., P.O. Box 1738, NL-3000 DR, Rotterdam, The Netherlands, knapp@ese.eur.nl or franses@.ese.eur.nl
} 


\section{Introduction and formulation of research question}

In the shipping industry the legislative framework is complex, and, due to its international nature, enforcement can be weak. The legislative framework of about 50 conventions is developed by the International Maritime Organization (IMO) who is the regulator of the shipping industry but lacks enforcement powers and does not directly monitor performance of its member states. Preventive actions, despite some effort made by IMO's member states to change this process, are still uncommon. This results in the creation or amendment of legislation being reactive, and typically following the outcome of a major disaster (oil tanker disaster, ferry disaster).

Action is usually taken after major disasters. After a negotiation process, the measures are agreed upon and the convention is adopted. After adoption, it normally will then take two to five years until it enters into force. Another important aspect of the regulatory process is the establishment of a system which compares the costs associated with the development of a measurement with the benefits so as to maximize social welfare (see Goulielmos and Giziakis [1]). According to these authors and in the context of preventing accidents, the "optimum level of acceptable accidents" should be determined. This level is determined by finding the minimum of the total costs associated with accidents where total costs is the total of the costs related to the accident and the accident prevention costs.

Following this concept, IMO, in the years 2001 and 2002, approved guidelines for the application of Formal Safety Assessment (FSA) for use in the IMO rule-making process. FSA is a rational and systematic process for assessing the risks relating to maritime safety and the protection of the marine environment and for evaluating the costs and benefits of IMO's options for reducing these risks. Application of FSA is limited to major changes in the regulative framework but its concept is to provide a proactive versus a reactive approach. Some of the major drawbacks of FSA studies are the lack of adequate data for proper analysis of risk factors and different applications of the guidelines.

Besides the development of FSA and its shortcomings, and notwithstanding the lack of enforcement, IMO through its technical cooperation committee (TCC) provides training and support to its member states. In this respect, IMO also developed the Voluntary Member States Audit Scheme (VMSAS) which should provide a better mechanism to foster compliance.

IMO's latest developments at council level come in the form of the Strategic Plan for the Organization, of which the latest for the period 2008-2013 is based on Assembly Resolution A.989(25) [2] and sets out 13 broad strategic directions. Resolution A.990(25) [3] then provides the corresponding High Level Action Plan (HLAP) for the 2008-2009 biennium. Along with the strategic directions, IMO developed a set of 42 performance indicators (PI) to measure progress made in achieving its strategic directions.

Despite the various measures to identify potential weaknesses in the legislative framework, no methods have been developed to provide any bore defined insight into the effectiveness of legislation in force, irrespective of the level of enforcement. It is generally assumed that a stricter level of enforcement of legislation will achieve what legislation wanted to obtain in the first place but the effect itself has not been measured using proper econometric techniques for various types of conventions in shipping. We present both aspects in which we use the level of ratification of a certain convention by its parties and the timing of the entry into force of the legislative framework including relevant amendments over the given time period. 
Alternative attempts were made to provide insight into the effect of legislation related to the environment such as Young [4] who investigates the effectiveness of international environmental regimes by looking at causal connections and behavioral mechanisms. Eliopoulou and Papanikolaou [5] and Delautre et al. [6] provide some insights into the influence of regulations on the safety records of tankers.

There are however currently 50 conventions at IMO level and various ILO ${ }^{3}$ conventions, and hence a partial analysis will not allow for an understanding of the full process. In this article, we therefore develop a method which measures the effectiveness of all relevant IMO and ILO conventions in the area of safety, the environment, search and rescue and work related measures. We further aim to provide an answer to the question of the level of enforcement, and we thereby correct for variables which can also have an effect on safety such as safety inspections and ship economic cycles (see Bijwaard and Knapp [7] for both aspects). In section 2, we provide an introduction to regime design and present our underlying concepts along with a description of the dataset used in this analysis. In section 3, we develop the model, apply it to the data and present a discussion of the results. Section 4 provides a high level summary and some recommendations for the policy maker.

\section{Underlying concepts and dataset to measure effectiveness of conventions}

\subsection{Main underlying concepts}

In regime design, Mitchel [8] distinguishes between three phases, and these are the creation of the measures, the compliance to it and the measures taken in case of non-compliance. The compliance phase in some circumstances starts prior to enforcement while in other cases it will only start after some time after enforcement. The degree of compliance will depend on the measures that are taken for non-compliance which also determines the effectiveness.

Despite the fact that the adoption/entry into force in normal circumstances will only apply to new ships, for some measures it applies to all ships or is staggered depending on the date of construction and ship type. Two types of measures can therefore be identified, that is, first, measures which take effect prior to entering into force and, second, measures which only become relevant after they are entered into force. An example for the first would be physical requirements with respect to the construction or conversions of vessels (e.g. single hull tanker phase out, Crude Oil Washing, Segregated Ballast Tank) while a classic example for the second would be the implementation of the ISM code or anything related to operational changes of the vessel.

In the long run, the effect of certain measures of a convention can be grouped into measuring the effect on certain types of casualties. Vessels with good safety management are expected to have less serious casualties or casualties with less pollution.

\subsection{Dataset created for our analysis}

The underlying dataset for the analysis follows the concepts above and is based on 50,367 casualties for a time period 1977 to 2007 of monthly data from IMO, Lloyd's Register Fairplay (LRF) and Lloyd's Maritime Intelligence Unit (LMIU) where only the whole time

\footnotetext{
${ }^{3} \mathrm{ILO}=$ International Labor Organization
} 
period is covered by LRF data. The dataset was also extended by including detention information from six port state control regimes when data was available.

Casualties can either be split up into the seriousness of the casualty (very serious, serious, less serious) or by casualty category (e.g. collision, contact, fire, hull related failures, pollution, loss of life and so on). For the classification of seriousness, we use IMO definitions according to MSC/Circ. 953, MEPC/Circ. 372 [9] and MSC Resolution MSC.255(84) [10] ${ }^{4}$. Pollution data was combined by using data from LRF, the International Tanker Owners Pollution Federation (ITOPF) and the Energy Related Safety Accident Database (ENSAD). For the classification of the casualty types, the data was reclassified whenever the first event could be identified. It is worth noticing at the classification of seriousness can be interpreted with more confidence in comparison to the casualty types.

In addition, the dataset also accounts for ship economic cycles based on data received from Clarksons which is one of the main brokers in the shipping industry. In constructing the variables, we follow the methodology explained in Bijwaard and Knapp [7] and account for inflation rates ${ }^{5}$ for the USD for the time frame on hand and deflate the nominal values. We then complement the time series with ship particular information from LRF and information on the adoption and ratification of flags to the international conventions and protocols from the IMO and ILO home pages [11]. The various types of variables and derivation of dependent variables for the econometric analysis will be explained in detail in section 3 .

\subsection{The creation of milestones of the legislative framework}

Appendix 1 provides an overview of the development of the legislative framework in the shipping industry along with a link to some of the major disasters which triggered legislation. The types of events can be classified as follows:

- Type 1: International conventions with their respective amendments

- Type 2: Unilateral legal instruments (e.g. EU regulations, US law)

- Type 3: Creation of port state control regimes who perform inspections

- Type 4: Creation of industry driven inspections (SIRE, CDI, RightShip)

One can observe various phases in the development of the framework. Initially, more emphasis was given to technical issues which were then expanded to pollution topics after a series of oil tanker disasters in the 70's. Only in recent years other pollution areas are considered (e.g. air pollution). Safety management and human-related issues only obtained the attention of regulators in recent years. The average time between adoption and entry into force is given by 3.1 years for all legal instruments listed in Appendix 1 .

The conventions and amendments are linked to casualty areas and the aim is to filter out the effect of the convention corrected by other factors that could have an effect (e.g. other safety inspections or the economic situation of the shipping markets - in particular earnings). We also account for the different time periods from adoption to entry into force and the number of flags which have ratified conventions of interest.

\footnotetext{
${ }^{4}$ The Maritime Safety Committee (MSC84) adopted MSC Resolution 255(84) on 16 May 2008 where the definitions were slightly changed and no longer distinguish between serious and less serious casualties. The definition for very serious casualty remains however unchanged. The reporting requirements will also change in the future.

${ }^{5}$ Historical monthly inflation rates can be obtained from http://www.inflationdata.com
} 
Important amendments to legislation and other events which can influence the level of safety and pollution prevention are identified and a set of milestones (MS) are identified [12] which forms the basis of the econometric analysis which we will perform in section 3 . The 45 milestones are listed in Table 1 with their respective adoption and entry into force dates. We also show starting dates of other events as well as a miles stone areas which will be used in the evaluation of the effects when we present our policy recommendations.

Table 1: Summary of Milestones used in the analysis

\begin{tabular}{|c|c|c|c|c|c|}
\hline Nr. & Main Events of interest & in response to & $\begin{array}{c}\text { Adoption } \\
\text { date }\end{array}$ & $\begin{array}{l}\text { Entry into } \\
\text { force date }\end{array}$ & Mile stone area \\
\hline 1 & LOAD LINES 66 Conv. & & $05 / 04 / 1966$ & $21 / 07 / 1968$ & Technical \\
\hline 2 & TONNAGE 69 Conv. & & $23 / 06 / 1969$ & $18 / 07 / 1982$ & Technical \\
\hline 3 & COLREG 72 Convention & & $20 / 10 / 1972$ & $15 / 07 / 1977$ & Navigation \\
\hline 4 & SOLAS 74 Convention & Titanic (1912) & $01 / 11 / 1974$ & $25 / 05 / 1980$ & Technical \\
\hline 5 & ILO147 MinSt 1976 & & 29/10/1976 & $28 / 11 / 1981$ & human related \\
\hline 6 & MARPOL 73/78 AI & Torrey Can. (1968) & $17 / 02 / 1978$ & $02 / 10 / 1983$ & Pollution \\
\hline 7 & MARPOL 73/78 AII & Torrey Can. (1968) & $17 / 02 / 1978$ & 06/04/1987 & Pollution \\
\hline 8 & MARPOL 73/78 AIII & & $17 / 02 / 1978$ & 01/07/1992 & Pollution \\
\hline 9 & SOLAS Protocol 78 & & $17 / 02 / 1978$ & $01 / 05 / 1981$ & Technical \\
\hline 10 & STCW 78 Convention & & 07/07/1978 & $28 / 04 / 1984$ & human related \\
\hline 11 & SAR Convention. & & $27 / 04 / 1979$ & $22 / 06 / 1985$ & search \& rescue \\
\hline 12 & SOLAS 81-11 Amend & Amoco Cadiz (1978) & $20 / 11 / 1981$ & $01 / 09 / 1984$ & technical \\
\hline 13 & Paris MoU starts & Amoco Cadiz (1978) & $26 / 01 / 1982$ & $01 / 07 / 1982$ & safety/pollution \\
\hline 14 & IBC Code mandatory & & $05 / 12 / 1985$ & 06/04/1987 & technical/pollution \\
\hline 15 & SOLAS 88-11 Amend & & $11 / 11 / 1988$ & $01 / 02 / 1992$ & search \&rescue \\
\hline 16 & SOLAS 88-Protocol & & $11 / 11 / 1988$ & $03 / 02 / 2000$ & safety mgtm \\
\hline 17 & LOAD Line 88-Protocol & & $11 / 11 / 1988$ & $03 / 02 / 2000$ & safety mgtm \\
\hline 18 & OPA 90 & Exxon Valdez (1989) & $01 / 08 / 1990$ & $01 / 08 / 1990$ & pollution \\
\hline 19 & MARPOL 92 Amend & Exxon Valdez (1989) & $06 / 03 / 1992$ & 06/07/1993 & pollution \\
\hline 20 & Viña del Mar starts & & $05 / 11 / 1992$ & $05 / 11 / 1992$ & technical/pollution \\
\hline 21 & SIRE starts & Exxon Valdez (1989) & $\mathrm{n} / \mathrm{a}$ & $01 / 01 / 1993$ & technical/pollution \\
\hline $22 \mathrm{a}$ & SOLAS 93-11 Amend1 & Herald of FE (1987) & $01 / 11 / 1993$ & 01/07/1998 & safety mgtm \\
\hline $22 b$ & SOLAS 93-11 Amend2 & Herald of FE (1987) & $01 / 11 / 1993$ & $01 / 07 / 2002$ & safety mgtm \\
\hline 23 & Tokyo MoU starts & & $01 / 12 / 1993$ & $01 / 01 / 1994$ & technical/pollution \\
\hline 24 & USCG emphasis on PSC & & $\mathrm{n} / \mathrm{a}$ & $01 / 01 / 1994$ & technical/pollution \\
\hline 25 & CDI starts inspections & & $\mathrm{n} / \mathrm{a}$ & $10 / 01 / 1994$ & technical/pollution \\
\hline 26 & SOLAS 94-05 Amend & & $01 / 05 / 1994$ & $01 / 01 / 1996$ & technical \\
\hline 27 & STCW 95 Amend & Estonia (1994) & $07 / 07 / 1995$ & $01 / 02 / 1997$ & safety mgtm \\
\hline 28 & SOLAS 95-11 Amend & Estonia (1994) & $29 / 11 / 1995$ & $01 / 07 / 1997$ & technical \\
\hline 29 & SOLAS 96-06 Amend & & $04 / 06 / 1996$ & $01 / 07 / 1998$ & safety/technical \\
\hline 30 & SOLAS 96-12 Amend & & $06 / 12 / 1996$ & $01 / 07 / 1998$ & safety/technical \\
\hline 31 & Caribbean MoU starts & & 09/02/1996 & 09/08/1996 & technical/pollution \\
\hline 32 & ILO 147 Prot 1996 & & $22 / 10 / 1996$ & $10 / 01 / 2003$ & human related \\
\hline 33 & Mediterranean MoU starts & & $11 / 07 / 1997$ & $23 / 02 / 1998$ & technical/pollution \\
\hline 34 & SOLAS 97-11 Amend & Derbyshire (1980) & $27 / 11 / 1997$ & 01/07/1999 & technical \\
\hline 35 & Indian Ocean MoU starts & & $05 / 06 / 1998$ & $22 / 01 / 1999$ & technical/pollution \\
\hline 36 & MARPOL 99 Amend & & 01/07/1999 & $01 / 01 / 2001$ & technical/pollution \\
\hline 37 & STCW White List published & & $\mathrm{n} / \mathrm{a}$ & $06 / 02 / 2000$ & human related \\
\hline 38 & Black Sea MoU start s & & $07 / 04 / 2000$ & $07 / 10 / 2000$ & technical/pollution \\
\hline 39 & MARPOL 01 Amend & Erika (1999) & $27 / 04 / 2001$ & $01 / 09 / 2002$ & pollution \\
\hline 40 & RightShip starts vetting & & $\mathrm{n} / \mathrm{a}$ & $01 / 10 / 2001$ & technical \\
\hline 41 & EC Regulation $417 / 2002$ & Erika (1999) & $18 / 02 / 2002$ & $01 / 09 / 2002$ & pollution \\
\hline 42 & SOLAS 02-12Amend & Derbyshire (1980) & $12 / 12 / 2002$ & $01 / 07 / 2004$ & technical \\
\hline 43 & EC Regulation $1726 / 2003$ & Erika, Prestige (2002) & $22 / 07 / 2003$ & $21 / 10 / 2003$ & pollution \\
\hline 44 & MARPOL 03 Amend & Erika, Prestige (2002) & $04 / 12 / 2003$ & $05 / 04 / 2005$ & pollution \\
\hline 45 & SOLAS 04-12 Amend & & $01 / 12 / 2004$ & $01 / 07 / 2006$ & technical \\
\hline
\end{tabular}

Source: compiled from various sources by authors 
The milestones are briefly explained in the paragraphs that follow in chronological order and by types of events. We start with the international conventions and their respective amendments followed by unilateral regional measures, port state control and industry inspections and exclude security related measures.

International Convention on Load Lines (1966) and Protocol (1988): The load line convention deals with limitations on draught (freeboards) up to which a ship can be loaded as well as external weather tight and watertight integrity of the vessel. As such, the convention tries to eliminate excess stress on the hull of the ship and tries to ensure adequate stability of the ship. The 1988 Protocol provides harmonized certification and survey requirements between the load line convention and other conventions (SOLAS and MARPOL) so that the time a ship needs to spend out of service due to a mandatory survey is reduced.

\section{International Convention on Tonnage Measurement of Ships (TONNAGE 69)}

It took considerable time for the Tonnage convention to come into force which reflects the complexity to develop a system to calculate the gross and net tonnage of a ship. These items needed harmonization on an international level due to the fact that both tonnages are used to calculate harbor dues. The new system had to be adopted so that it did not interfere too much with the old system. It is assumed that the convention also has an effect on safety due to the influence it had on the design on ships to reduce tonnage and associated harbor dues. We will test this in our models for the three major ship types.

Convention on the International Regulations for Preventing Collisions at Sea (COLREG 72): COLREG provides a set of rules in order to prevent collision at sea. It covers rules and regulations in any condition of visibility which states the rules the ships have to comply to prevent collision. The convention has four annexes dealing with technical details for lightening positioning, sound and signal appliances and distress signals.

International Convention for the Safety of Life at Sea (SOLAS 74) and Protocols (1978 and 1988): The creation of the SOLAS convention is partly influenced by the Titanic (1912) incident and is one of the most important conventions and contains twelve chapters specifying minimum standards for the construction, equipment and operation of ships. The convention itself has been amended numerous times and we take several of such amendments into account. We focus on safety-related measures and exclude security-related measures and the adoption of the IMO voluntary member state audit scheme which was adopted in 2005 where the period is too short to measure the effect. The identified milestones are as follows:

- 1978-Febr. Protocol: deals with several amendments for tankers and strengthens the surveys and the port state control requirements.

- 1981-Nov. Amendment: in response to the Amoco Cadiz (1978) incident, this amendment introduces improved requirements for fire safety, machinery and electrical installations as well as additional requirements concerning the carriage of navigational equipment.

- 1988-Nov. Protocol: the 1988 links up with the Load Line Protocol of 1988 to facilitate harmonized surveys for all ships under SOLAS, MARPOL and the Load Line Convention.

- 1988-Nov Amendment: introduction of the Global Maritime Distress and Safety System (GMDSS) to improve search and rescue.

- 1993-Nov. Amendment: influenced by the Herald of Free Enterprise (1987), IMO adopts the International Safety Management Code by Assembly Resolution 
A.741(18). The ISM code establishes a safety management system for all ship types with two different entries into force dates.

- 1994-Apr. Amendment: the amendment introduces the Enhanced Survey Program (ESP) by adoption of Assembly Resolution A.744(18) and makes the ISM Code mandatory. ESP should ensure better hull integrity by paying attention to corrosion and thickness of hull plates.

- 1995-Nov. Amendment: in response to the Estonia (1994) accident, improved stability requirements, lifesaving appliances and communication systems for passenger ships were adopted.

- 1997-Nov. Amendment: in response to the Derbyshire (1980) accident, additional safety measures for bulk carriers are adopted via a new chapter in SOLAS (chapter XII), adoption of the Code of Practice for the Safe Loading and unloading of bulk carriers (BLU Code, Assembly Resolution A.862(20))

- 1996-June and Dec Amendments: The amendments introduce a revised chapter on life-saving appliances and a new International Life-Saving Appliance Code (LSA) is introduced. The December Amendments introduce new fire safety measures and make the International Code for Application of Fire Test Procedures mandatory.

- 2002-Dec. Amendment: influenced by the Derbyshire accident, further amendments are made for additional safety measures for bulk carriers (high level alarms and water ingress systems based on MSC Resolution MSC.145(77), additional measures for the construction, fire protection and life saving appliances for other ship types.

- 2004-Dec. Amendment: improve bulk carrier safety, new requirements related to double side skins, free fall lifeboat mandatory for bulk.

Merchant Shipping (Minimum Standards) Convention (ILO Convention No. 147, 1976) and Protocol 1996: The Merchant Shipping (Minimum Standards) Convention from the ILO applies to seafarers on foreign flagged vessels. Its primary concern is to ensure safe working conditions and a minimum standard of onboard living conditions in order to ensure the safety of life onboard the vessel. The protocol of 1996 extends the coverage of the original convention including updated conventions on accommodation for crews, working hours, workers representation and health protection and medial care. The 2006 Maritime Labor Convention will replace the old system once it comes into force and it is not taken into consideration in our analysis.

International Convention for the Prevention of Pollution from Ships (MARPOL 73/78) with Annexes I-VI: MARPOL's creation was influenced by the Torrey Canyon (1968) incident and its prime aim is to prevent pollution from ships either caused due to an accident or due to normal operations. The convention is split into six relevant Annexes of which only the first three are taken into consideration in our analysis and they are as follows: Annex I: Prevention of Pollution by Oil, Annex II: Control of Pollution by Noxious Liquid Substances in Bulk (NLS), Annex III: Prevention of Pollution by Harmful Substances in Packaged Form, Annex IV: Prevention of Pollution by Sewage from Ships, Annex V: Prevention of Pollution by Garbage from Ships and Annex VI: Prevention of Air Pollution from Ships.

Annex I was amended by the Protocol of 1978 which introduced the SBT, COW and CBT requirements. Annex II provides a list of dangerous substances and their discharge criteria and makes the International Code for the Construction and Equipment of Ships Carrying Dangerous Chemicals in Bulk (IBC Code) mandatory.

\footnotetext{
${ }^{6}$ SBT: segregated ballast tanks, COW: crude oil washing, CBT: clean ballast tanks
} 
MARPOL has been amended many times but the most important amendments are the ones in response to the Exxon Valdez (1989) incident, the Erika (1999) incident and the Prestige (2002) incident. The amendments starting in 1992 up to 2003 deal with the phasing out of single hull tankers. Depending on the size and age of the vessel, the last amendment of 2003 provides a time table for this process. By 2010 at the latest, all single hull oil tankers have to be phased out. For the purpose of this article, we concentrate on the overall effect of MARPOL Annex I, II, III, the $\mathrm{IBC}^{7}$ Code, the phase out of single hull tankers and the establishment of the condition assessment program (CAS).

International Convention on Standards of Training, Certification and Watchkeeping for Seafarers (STCW 78): This convention tries to ensure a minimum standard for training, certification and watchkeeping for seafarers on an international level. The convention is accompanied by the STCW Code which gives a minimum standard for competence for personnel onboard a ship and has a mandatory part and a non-mandatory part. The IMO maintains a list of countries ("White List") which have given full effect to the STCW Convention (STCW 95). Countries on the "White List" can refuse to accept a seaman with a certificate of competence that is from a country not on the "White List".

The International Convention on Maritime Search and Rescue (SAR 1979): This convention established an international search and rescue plan so that help can reach vessels in distress as fast as possible and lives can be saved. The convention divides the world into thirteen areas of which members to the convention conduct their search and rescue actions.

With respect to the type 2 events, three unilateral legal instruments have been identified and are also included in the analysis. The first one is the Oil Pollution Act (OPA 90) which is the response of the United States of America to the Exxon Valdez disaster. In the European Union and in response to Erika and Prestige, unilateral action was given by EC Regulation 417/2002 and EC Regulation 1726/2003. All measures introduce stricter requirements for oil tankers trading in US waters and EU waters which also have a global impact since both are important trading areas. As the amendments of MARPOL contain the development of the EC regulations, we only incorporate OPA90 into the models.

The final events of interest for the analysis are the type 3 and type 4 events dealing with the creation of the inspection regimes. Safety inspections can be divided into mandatory and industry inspections which may overlap (see Knapp and Franses [13] for a detailed analysis of inspections). For the purpose of this analysis, we concentrate on the development of the PSC regimes and industry vetting inspections as follows.

- 1982: in response to the Amoco Cadiz (1978) incident, the Paris Memorandum of Understanding $(\mathrm{MoU})$ is created and covers Europe and the North Atlantic region

- 1992: the Viña del Mar Agreement was created and covers Latin America

- 1993: SIRE starts vetting inspections on oil tankers

- 1993: the Tokyo MoU is created and covers Asia and the Pacific region

- 1994: the USCG puts emphasis on foreign vessel inspection program

- 1994: CDI starts vetting inspections on chemical and oil tankers

- 1996: the Caribbean MoU is created

- 1997: the Mediterranean MoU is created

- 1998: the Indian Ocean MoU is created including parts of East Africa and Australia

- 2000: the Black Sea MoU is created

${ }^{7} \mathrm{IBC}=$ Code for the Construction and Equipment of Ships Carrying Dangerous Chemicals in Bulk 
- 2001: RightShip starts vetting inspections on dry bulk carriers

The Riyadh MoU, although signed in 2004 and which encompasses the Arab States of the Gulf, is not taken into consideration in this analysis as only very few inspections are carried out. The same applies for the Abjua MoU for the West and Central African region which was signed in 1999. For the econometric analysis, we use one an indicator covering the period of PSC inspections, namely the Paris MoU (1982 onwards) but we also incorporate detention data from six different PSC inspection regimes where data was available.

CDI inspections are performed by the Chemical Distribution Institute and SIRE inspections are performed by OCIMF (Oil Companies International Marine Forum). Both are based on a standardized questionnaire covering all areas of shipboard operations and are primarily for oil and chemical tankers. RightShip is a ranking system for dry bulk carriers which combine information obtained through vetting inspections, port state control, casualties, ship particular information and ship owner information. A RightShip Inspection covers all aspects of shipboard operations in addition to ship structure and cargo handling equipment including hatch covers which is important for dry bulk carriers.

\section{Methods to measure effectiveness of conventions}

\subsection{Details of the variables and model type combinations}

The dataset described in section 2 was used to create monthly figures for the time period January 1977 to December 2007. A full list of variables is given in Appendix 2 which groups the variables into variable groups and provides the variable types (e.g. monthly average, sums, dummy variable (0/1) etc.) for easier identification.

Each variable group represents a set of variables used in the models and which are either the variables of interest to measure effectiveness of conventions, the effect of ratification of the convention and a set of variables which are used as correction factors. The latter variables represent actions that influence safety besides the conventions and deal with enforcement (PSC and industry inspections) or ship economic cycles. In this way, the effect of interest should be filtered out. The variables are grouped as follows:

\section{Variables of interest}

- Indicators for entry into force of legal instruments and amendments $(0$ before, 1 from the time of entry onwards)

- Indicators for interim periods between adoption and entry into force ( 0 before, 0 after, and 1 in between)

- Number of IMO member states which have ratified a legal instrument or protocol (count)

\section{Correction factors}

- Ship particulars (age and gross tonnage)

- Indicators for starting periods of safety inspections (PSC and industry inspections) (0 before, 1 from the start onwards)

- Average earnings per months which represent the ship economic cycles

- Seasonal dummy variables for the month January to December (1 in season, 0 in other seasons) 
Table 2 provides a list of the different types of combinations of the models which lists the conventions and the different dependent variables $(D V)$ of the model combinations. We distinguish between four model types - type A for SOLAS, type B for MARPOL and type C for all other conventions. Type D models are combination models or models with specific interest such as the effect of conventions on fire \& explosions, hull related failures or machinery related failures. In these models, we also combine SOLAS and MARPOL.

Table 2: Combinations of models and dependent variables

\begin{tabular}{|c|c|c|c|}
\hline model & convention & ship types & Description of dependent variable (DV) - values per month \\
\hline A1: & SOLAS & all ship types & sum of very serious casualties/total ships \\
\hline A2: & SOLAS & all ship types & sum of serious casualties/total ships \\
\hline A3: & SOLAS & all ship types & sum of less serious casualties/total ships \\
\hline A4: & SOLAS & dry bulk & sum of casualties - dry bulk/total ships \\
\hline A5: & SOLAS & general cargo & sum all casualties - general cargo/total ships \\
\hline A6 & SOLAS & tanker & Sum of casualties - tanker/total ships \\
\hline A7: & SOLAS & container & sum of casualties - container/total ships \\
\hline A8: & SOLAS & passenger & sum of casualties - passenger ships/total ships \\
\hline B1: & MARPOL & all ship types & sum of casualties with pollution/total ships \\
\hline B2: & MARPOL & tankers & sum of very serious casualties of tankers/total ships \\
\hline B3: & MARPOL & tankers & tonnes of chemical pollution (LRF) \\
\hline B4: & MARPOL & tankers & tonnes of oil pollution (ENSAD, LRF and ITOPF) \\
\hline C1: & SAR & all ship types & sum of total loss of life \\
\hline $\mathrm{C} 2$ : & COLREG & all ship types & sum of collisions and contacts/total ships \\
\hline C3: & LOADLINE & all ship types & sum of hull related failures ${ }^{*} /$ total ships \\
\hline C4: & TONNAGE & dry bulk & sum of hull related failures ${ }^{*}$ for dry bulk carriers/total ships \\
\hline C5: & TONNAGE & tanker & sum of hull related failures ${ }^{*}$ for tankers/total ships \\
\hline C6: & TONNAGE & general cargo & sum of hull related failures ${ }^{*}$ for general cargo vessels/total ships \\
\hline C7: & STCW & all ship types & sum of very serious casualty types/total ships \\
\hline C8: & STCW & all ship types & sum of serious casualty types/total ships \\
\hline C9: & STCW & all ship types & sum of less serious casualty types/total ships \\
\hline C10: & ILO & all ship types & sum of very serious casualty types/total ships \\
\hline C11: & ILO & all ship types & sum of serious casualty types/total ships \\
\hline C12: & ILO & all ship types & sum of less serious casualty types/total ships \\
\hline D1: & Fire/Explosion & all ship types & sum of fire \& explosions/total ships \\
\hline D2: & Fire/Explosion & tankers & sum of fire \& explosions for tankers/total ships \\
\hline D3: & Hull related ${ }^{*}$ & tankers & sum of hull related failures ${ }^{*}$ for tankers/total ships \\
\hline D4: & Hull related ${ }^{*}$ & dry bulk & sum of hull related failures ${ }^{*}$ for dry bulk/total ships \\
\hline D5: & Machinery failure $^{\wedge}$ & all ship types & sum of engine machinery related failures/total ships \\
\hline
\end{tabular}

For the SOLAS type A models, we also include separate models per ship type for SOLAS and MARPOL. The dependent variables vary according to the legislative measures and can be defined by casualty type, casualty seriousness ${ }^{8}$, and loss of life or pollution.

The models for SOLAS, STCW and ILO contain all types of casualties excluding pollution with are dealt with in MARPOL. This is due to the fact that all three cover all areas of ship operation and it is assumed that adequate education (STCW) and working and living conditions (ILO) lead to less casualties for all casualty types. Separate models per seriousness type (very serious, serious and less serious) are created to see where legislation shows the strongest effect. For SOLAS, we also present separate models for the major ship types where the dependent variable is the sum of all casualty types per ship type.

\footnotetext{
${ }^{8}$ Casualty seriousness is defined as per IMO definitions into very serious, serious and less serious casualties.
} 
Furthermore, for the type C models, we use loss of life for SAR (search and rescue) and collisions and contacts for COLREG. With these models, we do not distinguish between ship types. For LOADLINE and TONNAGE which are conventions dealing with hardware related items such as hull integrity and the measurement of dimensions which affects the design of ships and therefore has an indirect effect on safety, casualties dealing with the hull integrity and related casualties are taken into consideration. For TONNAGE, we further provide a model for the three main ship types - dry bulk carriers, tankers and general cargo ships.

For the type B models dealing with pollution, several types of dependent variables are used. First we use the number of casualties with pollution for all ship types, and then we take a closer look at tankers and present a model on very serious casualties. Finally we also look at tonnes of pollution for chemicals and oil. The construction of the dependent variable for MARPOL requires some explanation. It is very difficult to obtain quality data for tons of pollution as the commercial data providers do not classify pollution categories in detail nor are there units recorded uniformly. At first hand, data from LRF and LMIU was obtained on a ship level where only data from LRF covered the whole time period. The data was then manually classified and converted into tons which lead to a total monthly figure for tons of oil and chemicals for the period on hand.

The oil pollution figures where then compared to ITOPF figures and figures from ENSAD the Energy Related Severe Accident Database. ENSAD was developed and maintained by the Scherrer Institute (PSI) in the mid 1990s and contains the most comprehensive database on energy related accidents. ENSAD contains data on spills of 700 tonnes and more while the ITOPF data contains spills of 7 tonnes and above and the raw data from LFF/LMIU is irrespective of the spill. In order to use the best possible combination of data, we combine the data from all sources and use average figures for oil pollution. For chemicals, only data from LRF was available and used accordingly.

Finally, the models for type D are specific models where we combine SOLAS and MARPOL related measured for fire and explosion on all ships and tankers and for hull related failures with respect to tankers. We also show machinery related failures for all ship types. These models should provide an overview on these three types of casualties versus the findings related to the seriousness of casualties.

\subsection{The econometric models}

For the general model used in this article, we use a standard regression model with a small adaptation for time series data. In time series, it is common to find serial correlation which is correlation of the error terms of the model. Serial correlation can lead to an underestimate of the standard errors of the parameters of interest (the coefficients) and can lead to an exaggeration of the significance thereof.

To correct for serial correlation and for short run dynamics within the time series, we include lagged variables for two periods $\left(D V_{t-1}\right.$ and $\left.D V_{t-2}\right)$ of the dependent variable $(D V)$. We use ordinary least squares (OLS) to estimate the parameters but in addition to the inclusion of the lagged variables, we also estimate the standard errors of the parameters by using NeweyWest HAC $^{9}$ standard errors and covariance which is a standard option in Eviews, the

\footnotetext{
${ }^{9} \mathrm{HAC}$ means heteroskedastistic and autocorrelation (serial correlation) consistent.
} 
software used to estimate the models. The basic model given in Equation 1 can be written in the form of

$$
y=\beta+\beta_{1} x+\beta_{2} y_{(-1)}+\beta_{3} y_{(-2)}+\varepsilon
$$

where $y$ is the dependent variable, $\beta$ is the intercept, $x$ are the explanatory variables with $\beta_{1}$ as the main coefficient of interest, $y_{(-1)}$ and $y_{(-2)}$ are the lagged variables of $y$ with $\beta_{2}$ and $\beta_{3}$ their respective coefficients and finally $\varepsilon$ are the residuals. We use the Breusch-Godfrey test (refer to Heij et al., chapter 5 for a detailed description [14]) to see how many lags should be included and find that two lags are usually sufficient. The final basic model is given in Equation 2 including the denotation of the explanatory variables.

We use the logarithm for the dependent variable, the lags and for scale variables such as grt, earnings and the number of countries which have ratified a convention. The model is changed according to the type of model given in Table 2 with different dependent variable $(D V)$ and explanatory variables. We use the same type of model across all conventions to facilitate interpretation of the parameters. Denotation of the variable groups is given below the equation where $k$ is an index from 1 to $n_{\ell}$ and $\ell$ represents the variable groups with total number of variables being $n_{\ell}$ within each group of $\ell$. The total number of $n_{\ell}$ depends on the model type and is indicated below with the relevant notation group.

$$
\begin{aligned}
\log (1+ & D V)_{t}=\beta_{0}+\beta_{2} \mathrm{AGE}_{\mathrm{t}}+\beta_{3} \log (\mathrm{GRT})_{\mathrm{t}}+\sum_{\mathrm{k}=1}^{n_{4}} \beta_{4, k} \mathrm{IN}_{k, t}+\sum_{\mathrm{k}=1}^{n_{5}} \beta_{5, k} \log \left(1+\mathrm{CR}_{k}\right)_{t} \\
& +\sum_{\mathrm{k}=1}^{n_{6}-1} \beta_{6, k} \mathrm{SEAS}_{k, t}+\beta_{7} \log (1+D V)_{t-1}+\beta_{8} \log (1+D V)_{t-2}+\beta_{9} \mathrm{PSC}_{\mathrm{t}}+\beta_{10} \log (1+\mathrm{det})_{\mathrm{t}} \\
& +\beta_{11} \mathrm{SIRE}_{\mathrm{t}}+\beta_{12} \mathrm{RS}_{\mathrm{t}}+\beta_{13} \mathrm{CDI}_{\mathrm{t}}+\beta_{14} \log (\mathrm{EARN})_{\mathrm{t}}+\sum_{\mathrm{k}=1}^{n_{15}} \beta_{15, k} \mathrm{AD}_{k, t}+\varepsilon_{\mathrm{t}}
\end{aligned}
$$

where

$D V=$ dependent variables as listed in table 2 (monthly data). We sometimes add 1 in case the DV takes the value 0)

$A G E, G R T=$ mean age (grt) of all ships or respective ship type (on average for vessels with incidents), for GRT, we use logs

$I N=$ dummy variable indicating when legal instrument entered into force ( 0 before and 1 after) where $n_{\ell}=31$

$C R=$ number of countries which have ratified a certain convention (amount per month) where $n_{\ell}=13$

$S E A S=$ seasonal dummies for months (we include February until December and set January as the benchmark) where $n_{\ell}=12$

$\log (1+D V)_{t-1}$ and $\log (1+D V)_{t-2}=$ lags 1 and 2 of the dependent variable to account for short-run dynamics

PSC, SIRE, RS, CDI = indicators that mark the start of port state control and industry inspections depending on the model (0 before, 1 from the start onwards)

Det $=$ number of detentions (per month) for all ships or respective ship type

$E A R N=$ earnings per month for all ship types or respective ship type

$A D=$ dummy indicating time between adoption and enforcement for certain measures where $n_{\ell}=14$

For the interpretation of the models, we concentrate on the parameters of interest which are in our case, the parameters $I N$ (indicators for entry into force of legal instruments), $A D$ (indicators for the timing between adoption and entry into force), $C R$ (the number of 
countries which have ratified a convention). We also comment on the results with reference $t$ the seasonal variables (SEAS).

By itself, $\beta_{1}$ of Equation 1 is called the short-run or immediate effect of $x$ which is the main parameter of interest for interpretation. The total or cumulative effect is given by a combination of the parameter of $\beta_{1}$ and the parameters of the lagged variables $\left(\beta_{2}\right.$ and $\left.\beta_{3}\right)$ in the form of $\beta_{1} /\left(1-\left(\beta_{2}+\beta_{3}\right)\right)$ only to be computed like this when the parameter of the lagged variable is unequal and smaller than (1). The total effect is a scale-free value, so its absolute value is not interesting, only its relative value to other total effects.

For the model diagnostics, we use the Breusch-Godfrey Serial Correlation LM Test to test for serial correlation (refer to Heij et al. [14] for a detailed explanation of the test). The results are given in Table 3 for each model type. One can still observe some serial correlation for some of the SOLAS models, COLREG, Tonnage (dry bulk) and the less serious models for STCW and ILO. As said, we use Newey-West HAC standard errors and covariance for the final models and believe that the serial correlation is not strong enough to influence the parameters. We prefer to keep the models the same across all conventions in order to facilitate interpretation.

Table 3: Results of Breusch-Godfrey Serial Correlation LM Test (12 lags)

\begin{tabular}{|l|l|r|l|l|r|}
\hline model & Convention & $\begin{array}{r}\text { LM-test } \\
\text { p value }\end{array}$ & model & Convention & $\begin{array}{r}\text { LM-test } \\
\text { p value }\end{array}$ \\
\hline A1: & SOLAS, very serious & 0.001 & C4: & Tonnage, dry bulk & 0.003 \\
A2: & SOLAS, serious & 0.001 & C5: & Tonnage, tanker & 0.025 \\
A3: & SOLAS, less serious & 0.027 & C6: & Tonnage, general cargo & 0.209 \\
A4: & SOLAS, dry bulk & 0.010 & C7: & STCW, very serious & 0.004 \\
A5: & SOLAS, general cargo & 0.012 & C8: & STCW, serious & 0.519 \\
A6 & SOLAS, tanker & 0.017 & C9: & STCW, less serious & 0.007 \\
A7: & SOLAS, container & 0.063 & C10: & ILO, very serious & 0.019 \\
A8: & SOLAS, passenger & 0.298 & C11: & ILO, serious & 0.030 \\
B1: & MARPOL, pollution & 0.157 & C12: & ILO, less serious & 0.009 \\
B2: & MARPOL, very serious & 0.421 & D1: & Fire/Explosion, all ships & 0.129 \\
B3: & MARPOL, chemicals & 0.028 & D3: & Fire/Explosion, tankers & 0.637 \\
B4: & MARPOL, oil & 0.141 & D4: & Hull related, tankers & 0.055 \\
C1: & SAR, loss of life & 0.006 & D5: & Machinery related, all ships & 0.055 \\
C2: & COLREG, collision \& contact & 0.011 & & & 0.078 \\
C3: & LOADLINE, hull related & & & \\
\hline
\end{tabular}

\subsection{Presentation and discussion of results}

This section presents the regression results of the models which are presented by model type in the tables that follow. We present the coefficients with standard errors and indicate the level of significance $(1 \%, 5 \%$ or $10 \%)$. Table 4 presents the results for SOLAS for the three level of seriousness of casualties while Table 5 presents the results per ship type.

The results with respect to the seriousness of casualties are mixed where some entry into force of conventions show a decreasing effect on the number of casualties, some show a positive effect and some are not significant. Not surprisingly, the strongest effect is related to very serious casualties for the entry into force of the SOLAS 74 Convention.

The introduction of the Global Maritime Distress and Safety System (GMDSS) via the SOLAS 88 Amendment show a decrease in the number of very serious and serious casualties but no effect on less serious casualties which is understandable. The SOLAS 93 Amendment 
with is dealing with the adoption of the ISM Code and introduced safety management to the shipping industry is negative for all three types of casualties and indicates that the adoption, entry into force and time between adoption and entry into force (given by the variable time to 93 Amend) has a negative effect on the number of casualties. On a ship type level, one can observe that the decrease applies primarily to dry bulk carriers and general cargo vessels but not to other ship types such as tanker, container vessels and passenger vessels.

Table 4: Type A Model Results - SOLAS, all ship types per seriousness

\begin{tabular}{|c|c|c|c|c|c|c|c|c|c|}
\hline & \multicolumn{3}{|c|}{ A1: very serious } & \multicolumn{3}{|c|}{ A2: serious } & \multicolumn{3}{|c|}{ A3: less serious } \\
\hline Variable & Coeff & SE & & Coeff & SE & & Coeff & SE & \\
\hline Intercept & -0.308 & 1.263 & & -1.654 & 1.146 & & -2.357 & 1.542 & \\
\hline AGE & 0.036 & 0.022 & $\wedge$ & 0.035 & 0.014 & $* *$ & -0.011 & 0.015 & \\
\hline GRT & -0.554 & 0.127 & $*$ & -0.251 & 0.102 & $*$ & -0.027 & 0.112 & \\
\hline 74 Convention & -3.387 & 2.018 & $\wedge$ & -1.652 & 1.674 & & 0.418 & 1.408 & \\
\hline 78 Protocol (inert gas) & 1.161 & 1.173 & & 1.349 & 0.942 & & 0.177 & 0.837 & \\
\hline 81 Amendment (fire measures) & 0.082 & 0.157 & & 0.184 & 0.147 & & -0.082 & 0.142 & \\
\hline 88 Protocol (HSSC) & 1.591 & 0.763 & $* *$ & -0.149 & 0.580 & & 2.047 & 1.126 & $\wedge$ \\
\hline 88 Amendment (GMDSS) & -0.405 & 0.134 & $*$ & -0.292 & 0.091 & * & -0.092 & 0.086 & \\
\hline 93 Amendment (ISM) & -0.239 & 0.106 & $* *$ & -0.240 & 0.121 & $* *$ & -0.358 & 0.156 & $* *$ \\
\hline 94 Amendment (ESP) & -0.011 & 0.048 & & -0.024 & 0.053 & & 0.021 & 0.066 & \\
\hline 95 Amendment (damage stab.) & 0.114 & 0.075 & & -0.095 & 0.072 & & -0.036 & 0.069 & \\
\hline 96 Amendment (LSA, Fire test) & -0.044 & 0.054 & & 0.085 & 0.072 & & 0.095 & 0.077 & \\
\hline 97 Amendment (add safety) & 0.086 & 0.184 & & 0.347 & 0.101 & $*$ & 0.002 & 0.165 & \\
\hline 02 Amendment (various) & 0.044 & 0.114 & & -0.083 & 0.089 & & -0.037 & 0.201 & \\
\hline 04 Amendment (add safety) & -0.125 & 0.068 & $\wedge$ & 0.137 & 0.062 & $* *$ & -0.203 & 0.141 & \\
\hline Time to 81 Amend. & 0.155 & 0.100 & & 0.199 & 0.105 & $\wedge$ & 0.013 & 0.101 & \\
\hline Time to 97 Amend. & -0.210 & 0.088 & $* *$ & -0.202 & 0.066 & $*$ & 0.108 & 0.055 & $* *$ \\
\hline Time to 93 Amend. & -0.172 & 0.056 & $*$ & -0.205 & 0.066 & $*$ & -0.051 & 0.054 & \\
\hline Countries ratified 74 Conv. & 0.917 & 0.526 & $\wedge$ & 0.433 & 0.440 & & -0.108 & 0.365 & \\
\hline Countries ratified 78 Prot. & -0.424 & 0.406 & & -0.447 & 0.335 & & -0.057 & 0.286 & \\
\hline Countries ratified 88 Prot. & -0.525 & 0.203 & $*$ & 0.034 & 0.154 & & -0.426 & 0.291 & \\
\hline February & -0.221 & 0.070 & $*$ & -0.086 & 0.075 & & -0.143 & 0.071 & $* *$ \\
\hline March & -0.174 & 0.062 & $*$ & -0.060 & 0.066 & & -0.023 & 0.079 & \\
\hline April & -0.277 & 0.073 & * & -0.205 & 0.068 & $*$ & -0.129 & 0.068 & $\wedge$ \\
\hline May & -0.305 & 0.066 & * & -0.286 & 0.070 & $*$ & -0.140 & 0.082 & $\wedge$ \\
\hline June & -0.078 & 0.079 & & -0.194 & 0.072 & $*$ & -0.157 & 0.072 & $*$ \\
\hline July & -0.093 & 0.078 & & -0.022 & 0.071 & & -0.006 & 0.076 & \\
\hline August & -0.274 & 0.088 & $*$ & -0.081 & 0.067 & & -0.141 & 0.088 & \\
\hline September & -0.176 & 0.074 & $* *$ & -0.205 & 0.070 & $*$ & -0.090 & 0.089 & \\
\hline October & -0.133 & 0.082 & & -0.063 & 0.072 & & 0.001 & 0.078 & \\
\hline November & -0.084 & 0.081 & & -0.029 & 0.083 & & -0.054 & 0.089 & \\
\hline December & 0.029 & 0.077 & & 0.018 & 0.059 & & 0.080 & 0.077 & \\
\hline $\log (1+\mathrm{DV}) \mathrm{t}-1$ & 0.248 & 0.056 & $*$ & 0.427 & 0.061 & $*$ & 0.504 & 0.103 & $*$ \\
\hline $\log (1+D V) t-2$ & 0.233 & 0.048 & $*$ & 0.280 & 0.061 & $*$ & 0.013 & 0.101 & \\
\hline Earnings & 0.151 & 0.064 & $* *$ & 0.180 & 0.058 & $*$ & -0.049 & 0.080 & \\
\hline PSC & -0.016 & 0.108 & & 0.078 & 0.100 & & -0.045 & 0.083 & \\
\hline Detentions & -0.048 & 0.026 & $\wedge$ & -0.004 & 0.025 & & 0.018 & 0.065 & \\
\hline $\mathrm{R}^{2}$ of model & 0.858 & & & 0.865 & & & 0.790 & & \\
\hline
\end{tabular}

Note: $*=$ significant at $1 \%, * *=$ significant at $5 \%, \wedge=$ significant at $10 \%$

All other amendments are not significant with the exception of the SOLAS 04 Amendment which introduces improved bulk carrier safety and new requirements and makes the free fall lifeboat mandatory for bulk carriers. The latter shows a negative effect for very serious and serious casualties. The variables indicating the number of countries which had ratified a convention is positive for the SOLAS convention and negative for the 88 Protocol indicating that the number of countries who had ratified the convention and protocol show opposite effects to the entry into force variables. 
For some of the amendments to SOLAS, it is more interesting to look at the separate ship models given in Table 5. For dry bulk carriers, one can observe that the SOLAS convention in general, GMDSS, the ISM Code, the 2002 Amendments (additional safety measures for bulk carriers and high level alarms for water ingress) all show a negative effect on the number of casualties on dry bulk carriers.

For general cargo vessels, the ISM code and the SOLAS 02 Amendments show negative effects. With respect to GMDSS, while the entry into force is not significant, the time between adoption and entry into force shows a negative effect on the number of casualties on general cargo ships. The number of countries having ratified the convention and protocols however do not appear to be significant.

Tankers on the other hand show positive effects for almost all legal instruments which are significant. The only variable with negative effect is the number of countries which have ratified the 88 Protocol. For this ship type, the negative effect of the industry inspections is worth noticing. For passenger vessels, the SOLAS 88 Protocol, the 02 Amendments (additional measures for fire protection and life saving appliances) show negative effects as well as the number of countries which had ratified the 78 Protocol.

In summary, the SOLAS model show mixed results where the effect of entry into force can be measured for the SOLAS convention for very serious casualties and separately for dry bulk carriers. The ISM code including the time from adoption to entry into force presents a decreasing effect on all types of seriousness of casualties, especially for dry bulk carriers and general cargo vessels. The number of countries which have ratified the convention or protocol is mostly not significant. Finally, for all SOLAS models, seasonality matters and more casualties are associated with January then with any of the other months.

Table 6 presents the results for the models for MARPOL. With respect to the number of casualties with pollution (model B1), entry into force of MARPOL Annex I and II and the number of countries which had ratified the convention is not significant. However, the amendments for the phase out of the single hull tankers and the Condition Assessment Scheme (CAS) show a decreasing effect. The seasonal variables indicate that more incidents happen in December compared to April, May or September.

Type B2 model looks at tankers with respect to very serious casualties which by definition include significant pollution, loss of life or loss of the vessel. While Annex I and the number of countries which had ratified the convention is not significant, the amendments for the phase out of the single hull tankers as well as the revised phase out and CAS all show a decreasing effect including the time from adoption to entry into force. Type B4 model then presents the effect with respect to tonnes of oil pollution. The result indicate that the time from adoption to entry into force related to the phase out of single hull tankers decreased the amount of tonnes of oil due to accidental release.

Finally, the type B3 model measures the effect of MARPOL Annex II with respect to tonnes of chemical pollution. The model shows that entry into force of this Annex presents a negative effect while the number of countries which have ratified the convention is positive. Seasonality for this type of casualty is not significant. It is also worth noting that the explained variance of this model $\left(\mathrm{R}^{2}\right)$ is rather low and that interpretation of this model is to be taken with caution. This could be due to the fact that there is very little data on chemical pollution available. 
Table 5: Type A Model Results - SOLAS (dry bulk, general cargo, tanker, container and passenger ships)

\begin{tabular}{|c|c|c|c|c|c|c|c|c|c|c|c|c|c|c|c|}
\hline \multirow[b]{2}{*}{ Variable } & \multicolumn{3}{|c|}{ A4: dry bulk } & \multicolumn{3}{|c|}{ A5: general cargo } & \multicolumn{3}{|c|}{ A6: tanker } & \multicolumn{3}{|c|}{ A7: container } & \multicolumn{3}{|c|}{ A8: passenger } \\
\hline & Coeff & SE & & Coeff & SE & & Coeff & SE & & Coeff & SE & & Coeff & SE & \\
\hline Intercept & -7.426 & 2.146 & & -3.966 & 1.205 & & -7.330 & 1.192 & & -6.301 & 1.624 & & -6.566 & 1.229 & \\
\hline AGE & 0.018 & 0.011 & $\wedge$ & -0.012 & 0.010 & & -0.006 & 0.006 & & 0.004 & 0.009 & ** & 0.003 & 0.005 & \\
\hline GRT & -0.054 & 0.111 & & 0.158 & 0.081 & $\wedge$ & 0.063 & 0.068 & & 0.069 & 0.054 & & 0.011 & 0.041 & \\
\hline 74 Convention & -3.930 & 2.172 & $\wedge$ & -1.643 & 1.758 & & -0.919 & 1.570 & & -1.678 & 4.189 & & -1.741 & 3.063 & \\
\hline 78 Protocol (inert gas) & 3.762 & 1.392 & * & 1.339 & 1.009 & & 1.142 & 0.935 & & 1.088 & 2.658 & & 2.928 & 1.747 & $\wedge$ \\
\hline 81 Amendment (fire measures) & 0.154 & 0.194 & & 0.129 & 0.118 & & 0.121 & 0.142 & & 0.233 & 0.362 & & 0.507 & 0.281 & $\wedge$ \\
\hline 88 Protocol (HSSC) & 3.025 & 2.128 & & -0.319 & 0.663 & & 1.118 & 0.635 & $\wedge$ & -1.491 & 1.169 & & -1.435 & 0.785 & $\wedge$ \\
\hline 88 Amendment (GMDSS) & -0.236 & 0.137 & $\wedge$ & -0.066 & 0.072 & & -0.114 & 0.112 & & -0.191 & 0.204 & & -0.090 & 0.157 & \\
\hline 93 Amendment-1 (ISM) & -0.392 & 0.205 & $\wedge$ & $\mathrm{n} / \mathrm{a}$ & $\mathrm{n} / \mathrm{a}$ & & -0.146 & 0.123 & & $\mathrm{n} / \mathrm{a}$ & $\mathrm{n} / \mathrm{a}$ & & 0.158 & 0.233 & \\
\hline 93 Amendment-2 (ISM) & $\mathrm{n} / \mathrm{a}$ & $\mathrm{n} / \mathrm{a}$ & & -0.119 & 0.071 & $\wedge$ & $\mathrm{n} / \mathrm{a}$ & $\mathrm{n} / \mathrm{a}$ & & -0.158 & 0.166 & & $\mathrm{n} / \mathrm{a}$ & $\mathrm{n} / \mathrm{a}$ & \\
\hline 94 Amendment (ESP) & 0.258 & 0.138 & $\wedge$ & -0.017 & 0.068 & & -0.052 & 0.048 & & 0.031 & 0.123 & & 0.461 & 0.361 & \\
\hline 95 Amendment (damage stability) & -0.002 & 0.169 & & -0.107 & 0.072 & & -0.100 & 0.068 & & -0.234 & 0.187 & & -0.612 & 0.401 & \\
\hline 96 Amendment (LSA, Fire test.) & 0.285 & 0.159 & $\wedge$ & 0.086 & 0.083 & & -0.068 & 0.058 & & 0.236 & 0.204 & & 0.200 & 0.176 & \\
\hline 97 Amendment (add. safety, bulk) & 0.044 & 0.216 & & 0.213 & 0.062 & $*$ & 0.139 & 0.086 & $\wedge$ & 0.501 & 0.104 & * & 0.350 & 0.107 & * \\
\hline 02 Amendment (various) & -0.096 & 0.206 & & -0.138 & 0.074 & $\wedge$ & 0.024 & 0.107 & & -0.156 & 0.139 & & -0.270 & 0.134 & $* *$ \\
\hline 04 Amendment (add safety, bulk) & -0.007 & 0.116 & & 0.074 & 0.063 & & 0.131 & 0.111 & & 0.006 & 0.090 & & -0.081 & 0.110 & \\
\hline Time to 81 Amend. & 0.200 & 0.149 & & 0.200 & 0.084 & ** & 0.169 & 0.086 & ** & 0.170 & 0.269 & & 0.325 & 0.201 & $\wedge$ \\
\hline Time to 88 Amend. & -0.084 & 0.089 & & -0.104 & 0.056 & $\wedge$ & 0.061 & 0.083 & & -0.157 & 0.151 & & 0.074 & 0.095 & \\
\hline Time to 93 Amend.-1 & -0.131 & 0.087 & & $\mathrm{n} / \mathrm{a}$ & $\mathrm{n} / \mathrm{a}$ & & 0.177 & 0.097 & $\wedge$ & $\mathrm{n} / \mathrm{a}$ & $\mathrm{n} / \mathrm{a}$ & & 0.092 & 0.148 & \\
\hline Time to 93 Amend.-2 & $\mathrm{n} / \mathrm{a}$ & $\mathrm{n} / \mathrm{a}$ & & -0.085 & 0.043 & ** & $\mathrm{n} / \mathrm{a}$ & $\mathrm{n} / \mathrm{a}$ & & -0.167 & 0.127 & & $\mathrm{n} / \mathrm{a}$ & $\mathrm{n} / \mathrm{a}$ & \\
\hline Time to 95 Amend. & $\mathrm{n} / \mathrm{a}$ & $\mathrm{n} / \mathrm{a}$ & & $\mathrm{n} / \mathrm{a}$ & $\mathrm{n} / \mathrm{a}$ & & $\mathrm{n} / \mathrm{a}$ & $\mathrm{n} / \mathrm{a}$ & & $\mathrm{n} / \mathrm{a}$ & $\mathrm{n} / \mathrm{a}$ & & -0.474 & 0.337 & \\
\hline Time to 97 Amend. & 0.137 & 0.131 & & $\mathrm{n} / \mathrm{a}$ & $\mathrm{n} / \mathrm{a}$ & & $\mathrm{n} / \mathrm{a}$ & $\mathrm{n} / \mathrm{a}$ & & $\mathrm{n} / \mathrm{a}$ & $\mathrm{n} / \mathrm{a}$ & & $\mathrm{n} / \mathrm{a}$ & $\mathrm{n} / \mathrm{a}$ & \\
\hline Time to 02 Amend. & -0.213 & 0.127 & $\wedge$ & $\mathrm{n} / \mathrm{a}$ & $\mathrm{n} / \mathrm{a}$ & & $\mathrm{n} / \mathrm{a}$ & $\mathrm{n} / \mathrm{a}$ & & $\mathrm{n} / \mathrm{a}$ & $\mathrm{n} / \mathrm{a}$ & & $\mathrm{n} / \mathrm{a}$ & $\mathrm{n} / \mathrm{a}$ & \\
\hline Time to 04 Amend. & 0.058 & 0.236 & & $\mathrm{n} / \mathrm{a}$ & $\mathrm{n} / \mathrm{a}$ & & $\mathrm{n} / \mathrm{a}$ & $\mathrm{n} / \mathrm{a}$ & & $\mathrm{n} / \mathrm{a}$ & $\mathrm{n} / \mathrm{a}$ & & $\mathrm{n} / \mathrm{a}$ & $\mathrm{n} / \mathrm{a}$ & \\
\hline Countries ratified 74 Conv. & 1.083 & 0.572 & $\wedge$ & 0.421 & 0.462 & & 0.258 & 0.409 & & 0.482 & 1.108 & & 0.503 & 0.799 & \\
\hline Countries ratified 78 Prot. & -1.254 & 0.475 & * & -0.454 & 0.353 & & -0.400 & 0.327 & & -0.474 & 0.945 & & -1.019 & 0.620 & $\wedge$ \\
\hline Countries ratified 88 Prot. & -0.745 & 0.566 & & 0.060 & 0.177 & & -0.324 & 0.174 & $\wedge$ & 0.375 & 0.323 & & 0.466 & 0.210 & ** \\
\hline February & -0.134 & 0.085 & & -0.217 & 0.102 & ** & -0.146 & 0.052 & * & 0.013 & 0.115 & & 0.040 & 0.155 & \\
\hline March & -0.051 & 0.089 & & -0.199 & 0.118 & $\wedge$ & -0.040 & 0.040 & & 0.088 & 0.116 & & 0.051 & 0.134 & \\
\hline April & -0.172 & 0.090 & $\wedge$ & -0.321 & 0.108 & * & -0.184 & 0.044 & * & -0.159 & 0.125 & & -0.097 & 0.142 & \\
\hline May & -0.183 & 0.094 & $* *$ & -0.408 & 0.118 & * & -0.232 & 0.057 & * & -0.244 & 0.140 & $\wedge$ & -0.104 & 0.127 & \\
\hline June & -0.185 & 0.104 & $\wedge$ & -0.208 & 0.132 & & -0.234 & 0.050 & * & -0.105 & 0.107 & & 0.065 & 0.134 & \\
\hline July & -0.143 & 0.085 & $\wedge$ & -0.148 & 0.147 & & -0.133 & 0.056 & $* *$ & -0.082 & 0.132 & & 0.208 & 0.131 & \\
\hline August & -0.266 & 0.116 & $* *$ & -0.274 & 0.156 & $\wedge$ & -0.264 & 0.055 & $*$ & -0.123 & 0.127 & & 0.153 & 0.133 & \\
\hline September & -0.145 & 0.088 & $\wedge$ & -0.211 & 0.123 & $\wedge$ & -0.165 & 0.066 & ** & -0.126 & 0.131 & & -0.122 & 0.129 & \\
\hline October & -0.228 & 0.106 & $* *$ & -0.045 & 0.132 & & -0.121 & 0.047 & $* *$ & 0.044 & 0.118 & & -0.007 & 0.136 & \\
\hline November & -0.104 & 0.112 & & -0.088 & 0.153 & & -0.157 & 0.048 & $*$ & -0.007 & 0.137 & & 0.174 & 0.157 & \\
\hline December & 0.009 & 0.090 & & -0.047 & 0.138 & & -0.032 & 0.049 & & 0.092 & 0.134 & & 0.125 & 0.124 & \\
\hline $\log (1+D V) t-1$ & 0.251 & 0.064 & * & 0.461 & 0.082 & $*$ & 0.096 & 0.066 & & 0.231 & 0.066 & * & 0.214 & 0.087 & $* *$ \\
\hline $\log (1+D V) t-2$ & 0.189 & 0.087 & $* *$ & 0.272 & 0.071 & * & 0.048 & 0.059 & & 0.133 & 0.069 & $* *$ & 0.138 & 0.069 & $* *$ \\
\hline Earnings & 0.391 & 0.155 & ** & 0.116 & 0.056 & $* *$ & 0.093 & 0.042 & ** & -0.150 & 0.174 & & $\mathrm{n} / \mathrm{a}$ & $\mathrm{n} / \mathrm{a}$ & \\
\hline PSC & 0.295 & 0.136 & $* *$ & 0.127 & 0.091 & & 0.040 & 0.087 & & 0.339 & 0.288 & & 0.290 & 0.169 & $\wedge$ \\
\hline Detentions & -0.002 & 0.089 & & 0.001 & 0.021 & & 0.008 & 0.053 & & 0.002 & 0.087 & & 0.092 & 0.065 & \\
\hline SIRE & $\mathrm{n} / \mathrm{a}$ & $\mathrm{n} / \mathrm{a}$ & & $\mathrm{n} / \mathrm{a}$ & $\mathrm{n} / \mathrm{a}$ & & -0.090 & 0.093 & & $\mathrm{n} / \mathrm{a}$ & $\mathrm{n} / \mathrm{a}$ & & $\mathrm{n} / \mathrm{a}$ & $\mathrm{n} / \mathrm{a}$ & \\
\hline $\mathrm{RS}$ & 0.206 & 0.171 & & $\mathrm{n} / \mathrm{a}$ & $\mathrm{n} / \mathrm{a}$ & & $\mathrm{n} / \mathrm{a}$ & $\mathrm{n} / \mathrm{a}$ & & $\mathrm{n} / \mathrm{a}$ & $\mathrm{n} / \mathrm{a}$ & & $\mathrm{n} / \mathrm{a}$ & $\mathrm{n} / \mathrm{a}$ & \\
\hline CDI & $\mathrm{n} / \mathrm{a}$ & $\mathrm{n} / \mathrm{a}$ & & $\mathrm{n} / \mathrm{a}$ & $\mathrm{n} / \mathrm{a}$ & & -0.349 & 0.076 & * & $\mathrm{n} / \mathrm{a}$ & $\mathrm{n} / \mathrm{a}$ & & $\mathrm{n} / \mathrm{a}$ & $\mathrm{n} / \mathrm{a}$ & \\
\hline $\mathrm{R}^{2}$ of model & 0.553 & & & 0.760 & & & 0.903 & & & 0.461 & & & 0.599 & & \\
\hline
\end{tabular}

Note: $*=$ significant at $1 \%, * *=$ significant at $5 \%, \wedge=$ significant at $10 \%$ 
Table 6: Type B Model Results - MARPOL

\begin{tabular}{|c|c|c|c|c|c|c|c|c|c|c|c|c|}
\hline Variable & \multicolumn{3}{|c|}{$\begin{array}{c}\text { B1: all ships } \\
\text { casualties with pollution }\end{array}$} & \multicolumn{3}{|c|}{$\begin{array}{c}\text { B2: tankers } \\
\text { very serious casualties }\end{array}$} & \multicolumn{3}{|c|}{$\begin{array}{c}\text { B3: tankers } \\
\text { tonnes chemicals }\end{array}$} & \multicolumn{3}{|c|}{$\begin{array}{l}\text { B4: tankers } \\
\text { tonnes oil }\end{array}$} \\
\hline Intercept & -9.598 & 1.643 & & -11.377 & 1.555 & & -5.872 & 4.000 & & -2.172 & 2.242 & \\
\hline GRT & -0.052 & 0.133 & & 0.049 & 0.094 & & 0.188 & 0.384 & & 0.293 & 0.150 & $\wedge$ \\
\hline Marpol Annex I (oil) & 0.589 & 0.830 & & -0.844 & 1.148 & & $\mathrm{n} / \mathrm{a}$ & $\mathrm{n} / \mathrm{a}$ & & 0.016 & 1.435 & \\
\hline Marpol Annex II (NLS) & not incl & not incl & & not incl & not incl & & -0.625 & 0.354 & $\wedge$ & $\mathrm{n} / \mathrm{a}$ & $\mathrm{n} / \mathrm{a}$ & \\
\hline 99 Amend. (extension double hull) & 0.569 & 0.156 & ** & -0.550 & 0.280 & ** & $\mathrm{n} / \mathrm{a}$ & $\mathrm{n} / \mathrm{a}$ & & 0.195 & 0.470 & \\
\hline 01 Amend. (CAS, phase out) & -0.227 & 0.138 & $\wedge$ & -0.348 & 0.151 & $* *$ & $\mathrm{n} / \mathrm{a}$ & $\mathrm{n} / \mathrm{a}$ & & 0.260 & 0.342 & \\
\hline 03 Amend. (revised phase out) & -0.368 & 0.137 & $*$ & -0.412 & 0.150 & $*$ & $\mathrm{n} / \mathrm{a}$ & $\mathrm{n} / \mathrm{a}$ & & -0.300 & 0.198 & \\
\hline IBC code mandatory (chemicals) & -0.040 & 0.171 & & -0.354 & 0.243 & & not incl & not incl & & $\mathrm{n} / \mathrm{a}$ & $\mathrm{n} / \mathrm{a}$ & \\
\hline Opa 90 (US law) & 0.095 & 0.137 & & -0.154 & 0.116 & & $\mathrm{n} / \mathrm{a}$ & $\mathrm{n} / \mathrm{a}$ & & 0.397 & 0.308 & \\
\hline Time to 92 Amend. & 0.223 & 0.125 & $\wedge$ & -0.095 & 0.109 & & $\mathrm{n} / \mathrm{a}$ & $\mathrm{n} / \mathrm{a}$ & & 0.078 & 0.308 & \\
\hline Countries ratified Annex II & not incl & not incl & & not incl & not incl & & 0.122 & 0.068 & $\wedge$ & $\mathrm{n} / \mathrm{a}$ & $\mathrm{n} / \mathrm{a}$ & \\
\hline Countries ratified Annex III & -0.186 & 0.390 & & $\mathrm{n} / \mathrm{a}$ & $\mathrm{n} / \mathrm{a}$ & & $\mathrm{n} / \mathrm{a}$ & $\mathrm{n} / \mathrm{a}$ & & $\mathrm{n} / \mathrm{a}$ & $\mathrm{n} / \mathrm{a}$ & \\
\hline February & -0.097 & 0.099 & & -0.305 & 0.124 & $* *$ & -0.329 & 0.325 & & -0.429 & 0.319 & \\
\hline March & -0.095 & 0.112 & & -0.199 & 0.096 & $* *$ & -0.232 & 0.356 & & -0.246 & 0.280 & \\
\hline April & -0.208 & 0.121 & $\wedge$ & -0.317 & 0.104 & $*$ & 0.119 & 0.338 & & -0.283 & 0.256 & \\
\hline May & -0.294 & 0.125 & $* *$ & -0.191 & 0.110 & $\wedge$ & 0.130 & 0.413 & & -0.468 & 0.242 & \\
\hline June & -0.137 & 0.118 & & -0.179 & 0.116 & & 0.089 & 0.392 & & -0.114 & 0.257 & \\
\hline July & -0.082 & 0.108 & & -0.028 & 0.100 & & 0.092 & 0.384 & & 0.056 & 0.283 & \\
\hline August & -0.066 & 0.107 & & -0.359 & 0.112 & * & 0.076 & 0.452 & & -0.321 & 0.277 & \\
\hline September & -0.170 & 0.120 & $\wedge$ & -0.244 & 0.123 & $* *$ & -0.218 & 0.351 & & -0.252 & 0.281 & \\
\hline October & -0.145 & 0.113 & & -0.117 & 0.101 & & 0.284 & 0.437 & & -0.048 & 0.305 & \\
\hline November & -0.131 & 0.107 & & -0.128 & 0.087 & & -0.453 & 0.300 & & 0.099 & 0.296 & \\
\hline $\mathrm{R}^{2}$ of model & 0.239 & & & 0.623 & & & 0.059 & & & 0.564 & & \\
\hline
\end{tabular}


In summary, the MARPOL models indicate that the various amendments in relation with the phase out of single hull tankers and CAS decreased the number of casualties with pollution and to a certain degree also the amount of pollution. The effect of MARPOL Annex III cannot be measures but the number of countries who had ratified the convention shows a decreasing effect. Furthermore, the IBC code decreased casualties with relation to fire and explosion on tankers.

Table 7 presents the results of the type $\mathrm{C}$ models. For the SAR convention, entry into force does not show a negative effect while ratification does show a negative effect on the number of lives lost. The more countries ratify the convention, the more likely lives can be saved. For COLREG, the effect of the convention and number of countries which had ratified it cannot be measured. This could be due to the fact that COLREG came into force in July 1977 and the time frame to measure its effect is therefore too short.

For the LOADLINE convention, the results confirm that ratification matters and its effect is negative on the number of casualties for hull related issues and subsequent casualties which includes flooding, foundering, capsizing, wrecked, stranded, grounded and hull related failures in general. The TONNAGE convention is split into separate models for the main ship types. We do not include an indicator for the entry into force since it lies outside the time frame used for this analysis. However, ratification clearly shows a negative effect for all ship types with respect to hull related issues (the same dependent variable as for LOADLINE).

Table 8 presents the type $\mathrm{C}$ models which are related to human factors such as the working and living conditions of the crew (ILO) and the training of the crew (STCW). The models for STCW indicate that the introduction of the STCW White List by IMO has a negative effect on the number of very serious casualties but not serious and less serious casualties. Furthermore, ratification of the STCW 78 convention shows a negative effect for very serious and serious casualties while the entry into force shows a positive effect. We cannot measure the effect of the STCW95 amendment to the Convention. The results for the ILO 76 convention and 96 Protocol cannot be measured for any type of casualties but the number of countries which have ratified the ILO 96 Protocol have a decreasing effect on very serious casualties.

In summary, for the type $\mathrm{C}$ models, the number of countries which had ratified the SAR convention decreases the number of lives that are lost. The LOADLINE and TONNAGE conventions both improved the number of casualties related to hull related issues, the latter for all major ship types. This is reflected by the number of countries who have ratified the conventions. The number of countries which have ratified the STCW 78 Convention decreases very serious and serious casualties while the introduction of the STCW While List decreases the number of very serious casualties.

Finally, we cannot measure the effect of COLREG with the time frame used in this analysis and we also cannot measure the effect of the ILO convention. For the type C models, seasonality matters for the conventions dealing with SAR and hull related casualties as well as for the STCW and ILO conventions for very serious casualties. More lives are lost in January or more hull related casualties are found in the winter months. 
Table 7: Type C Model Results - SAR, Colreg, Loadline, Tonnage

\begin{tabular}{|c|c|c|c|c|c|c|c|c|c|c|c|c|c|c|c|c|c|c|}
\hline \multirow[b]{2}{*}{ Variable } & \multicolumn{3}{|c|}{ C1: SAR } & \multicolumn{3}{|c|}{ C2: COLREG } & \multicolumn{3}{|c|}{ C3: Loadline } & \multicolumn{3}{|c|}{$\begin{array}{l}\text { C4: Tonnage } \\
\text { dry bulk }\end{array}$} & \multicolumn{3}{|c|}{$\begin{array}{c}\text { C5: Tonnage } \\
\text { tanker }\end{array}$} & \multicolumn{3}{|c|}{$\begin{array}{l}\text { C6: Tonnage } \\
\text { general cargo }\end{array}$} \\
\hline & Coeff & SE & & Coeff & SE & & Coeff & SE & & Coeff & SE & & Coeff & SE & & Coeff & SE & \\
\hline Intercept & 9.144 & 4.402 & & -0.251 & 1.400 & & 3.702 & 1.037 & & -4.385 & 1.601 & & -3.199 & 0.917 & & -8.768 & 1.301 & \\
\hline AGE & 0.028 & 0.057 & & -0.053 & 0.013 & $*$ & 0.023 & 0.013 & $\wedge$ & 0.027 & 0.010 & $* *$ & -0.001 & 0.009 & & 0.007 & 0.011 & \\
\hline GRT & -0.883 & 0.433 & $* *$ & -0.317 & 0.110 & $*$ & -0.205 & 0.086 & $* *$ & -0.123 & 0.143 & & 0.125 & 0.053 & $* *$ & 0.230 & 0.094 & $* *$ \\
\hline Colreg 72 Convention & $\mathrm{n} / \mathrm{a}$ & $\mathrm{n} / \mathrm{a}$ & & 1.019 & 1.135 & & $\mathrm{n} / \mathrm{a}$ & $\mathrm{n} / \mathrm{a}$ & & $\mathrm{n} / \mathrm{a}$ & $\mathrm{n} / \mathrm{a}$ & & $\mathrm{n} / \mathrm{a}$ & $\mathrm{n} / \mathrm{a}$ & & $\mathrm{n} / \mathrm{a}$ & $\mathrm{n} / \mathrm{a}$ & \\
\hline Loadline 88 Protocol & $\mathrm{n} / \mathrm{a}$ & $\mathrm{n} / \mathrm{a}$ & & $\mathrm{n} / \mathrm{a}$ & $\mathrm{n} / \mathrm{a}$ & & -0.066 & 0.272 & & $\mathrm{n} / \mathrm{a}$ & $\mathrm{n} / \mathrm{a}$ & & $\mathrm{n} / \mathrm{a}$ & $\mathrm{n} / \mathrm{a}$ & & $\mathrm{n} / \mathrm{a}$ & $\mathrm{n} / \mathrm{a}$ & \\
\hline SAR 79 Convention & 2.682 & 1.497 & $\wedge$ & & & & $\mathrm{n} / \mathrm{a}$ & $\mathrm{n} / \mathrm{a}$ & & $\mathrm{n} / \mathrm{a}$ & $\mathrm{n} / \mathrm{a}$ & & $\mathrm{n} / \mathrm{a}$ & $\mathrm{n} / \mathrm{a}$ & & $\mathrm{n} / \mathrm{a}$ & $\mathrm{n} / \mathrm{a}$ & \\
\hline Countries ratified Colreg $72 \mathrm{C}$ & $\mathrm{n} / \mathrm{a}$ & $\mathrm{n} / \mathrm{a}$ & & -0.204 & 0.246 & & $\mathrm{n} / \mathrm{a}$ & $\mathrm{n} / \mathrm{a}$ & & $\mathrm{n} / \mathrm{a}$ & $\mathrm{n} / \mathrm{a}$ & & $\mathrm{n} / \mathrm{a}$ & $\mathrm{n} / \mathrm{a}$ & & $\mathrm{n} / \mathrm{a}$ & $\mathrm{n} / \mathrm{a}$ & \\
\hline Countries ratified Loadline $66 \mathrm{C}$ & $\mathrm{n} / \mathrm{a}$ & $\mathrm{n} / \mathrm{a}$ & & $\mathrm{n} / \mathrm{a}$ & $\mathrm{n} / \mathrm{a}$ & & -1.227 & 0.268 & * & $\mathrm{n} / \mathrm{a}$ & $\mathrm{n} / \mathrm{a}$ & & $\mathrm{n} / \mathrm{a}$ & $\mathrm{n} / \mathrm{a}$ & & $\mathrm{n} / \mathrm{a}$ & $\mathrm{n} / \mathrm{a}$ & \\
\hline Countries ratified Loadline 88P & $\mathrm{n} / \mathrm{a}$ & $\mathrm{n} / \mathrm{a}$ & & $\mathrm{n} / \mathrm{a}$ & $\mathrm{n} / \mathrm{a}$ & & 0.049 & 0.068 & & $\mathrm{n} / \mathrm{a}$ & $\mathrm{n} / \mathrm{a}$ & & $\mathrm{n} / \mathrm{a}$ & $\mathrm{n} / \mathrm{a}$ & & $\mathrm{n} / \mathrm{a}$ & $\mathrm{n} / \mathrm{a}$ & \\
\hline Countries ratified SAR 79C & -0.763 & 0.431 & $\wedge$ & $\mathrm{n} / \mathrm{a}$ & $\mathrm{n} / \mathrm{a}$ & & $\mathrm{n} / \mathrm{a}$ & $\mathrm{n} / \mathrm{a}$ & & $\mathrm{n} / \mathrm{a}$ & $\mathrm{n} / \mathrm{a}$ & & $\mathrm{n} / \mathrm{a}$ & $\mathrm{n} / \mathrm{a}$ & & $\mathrm{n} / \mathrm{a}$ & $\mathrm{n} / \mathrm{a}$ & \\
\hline Countries ratified Tonnage $69 \mathrm{C}$ & $\mathrm{n} / \mathrm{a}$ & $\mathrm{n} / \mathrm{a}$ & & $\mathrm{n} / \mathrm{a}$ & $\mathrm{n} / \mathrm{a}$ & & $\mathrm{n} / \mathrm{a}$ & $\mathrm{n} / \mathrm{a}$ & & -0.667 & 0.171 & $*$ & -0.455 & 0.178 & ** & -0.745 & 0.146 & * \\
\hline February & 0.135 & 0.259 & & -0.126 & 0.069 & $\wedge$ & -0.217 & 0.045 & $*$ & -0.338 & 0.103 & $*$ & -0.243 & 0.085 & $*$ & -0.258 & 0.088 & * \\
\hline March & -0.488 & 0.253 & $\wedge$ & 0.014 & 0.072 & & -0.203 & 0.048 & $*$ & -0.132 & 0.103 & & -0.277 & 0.103 & $*$ & -0.246 & 0.076 & $*$ \\
\hline April & -0.554 & 0.283 & $\wedge$ & -0.164 & 0.069 & ** & -0.319 & 0.053 & * & -0.256 & 0.101 & ** & -0.482 & 0.098 & * & -0.242 & 0.076 & * \\
\hline May & -1.333 & 0.237 & $*$ & -0.152 & 0.079 & $\wedge$ & -0.454 & 0.065 & $*$ & -0.413 & 0.128 & $*$ & -0.591 & 0.107 & $*$ & -0.488 & 0.083 & $*$ \\
\hline June & -0.415 & 0.229 & $\wedge$ & -0.153 & 0.068 & $* *$ & -0.222 & 0.077 & $*$ & -0.183 & 0.116 & & -0.214 & 0.136 & & -0.403 & 0.091 & $*$ \\
\hline July & -0.758 & 0.253 & $*$ & -0.053 & 0.073 & & -0.141 & 0.063 & $* *$ & -0.361 & 0.112 & $*$ & -0.067 & 0.125 & & -0.271 & 0.100 & $*$ \\
\hline August & -1.105 & 0.240 & $*$ & -0.214 & 0.082 & $* *$ & -0.233 & 0.062 & $*$ & -0.330 & 0.121 & $*$ & -0.287 & 0.127 & $* *$ & -0.328 & 0.083 & $*$ \\
\hline September & -0.715 & 0.306 & $* *$ & -0.260 & 0.074 & $*$ & -0.160 & 0.069 & $* *$ & -0.176 & 0.102 & $\wedge$ & -0.147 & 0.122 & & -0.162 & 0.093 & $\wedge$ \\
\hline October & -0.561 & 0.257 & $* *$ & -0.126 & 0.075 & $\wedge$ & -0.030 & 0.062 & & -0.225 & 0.099 & $* *$ & 0.047 & 0.121 & & -0.132 & 0.088 & \\
\hline November & -0.591 & 0.244 & $* *$ & -0.105 & 0.109 & & -0.042 & 0.076 & & -0.172 & 0.124 & & 0.088 & 0.109 & $*$ & -0.217 & 0.087 & $* *$ \\
\hline December & -0.285 & 0.333 & & -0.088 & 0.079 & & 0.109 & 0.051 & ** & -0.003 & 0.113 & & 0.047 & 0.115 & & 0.041 & 0.085 & \\
\hline $\log (1+\mathrm{DV}) \mathrm{t}-1$ & -0.024 & 0.059 & & 0.397 & 0.046 & * & 0.269 & 0.067 & $*$ & 0.273 & 0.053 & $*$ & 0.290 & 0.076 & $*$ & 0.172 & 0.048 & $*$ \\
\hline $\log (1+D V) t-2$ & -0.006 & 0.051 & & 0.139 & 0.049 & $*$ & 0.281 & 0.056 & $*$ & 0.203 & 0.044 & $*$ & 0.427 & 0.060 & $*$ & 0.132 & 0.053 & $* *$ \\
\hline Earnings & 0.377 & 0.192 & $\wedge$ & 0.079 & 0.044 & $* *$ & 0.065 & 0.036 & $\wedge$ & 0.103 & 0.063 & $\wedge$ & 0.007 & 0.038 & & 0.090 & 0.039 & $* *$ \\
\hline PSC & 0.158 & 0.287 & & 0.024 & 0.089 & & 0.072 & 0.061 & & 2.774 & 0.729 & * & 1.861 & 0.704 & * & 3.074 & 0.643 & $*$ \\
\hline Detentions & -0.003 & 0.042 & & 0.020 & 0.014 & & -0.003 & 0.016 & & 0.042 & 0.025 & $\wedge$ & 0.026 & 0.013 & $\wedge$ & -0.100 & 0.027 & * \\
\hline $\mathrm{R}^{2}$ of model & 0.158 & & & 0.578 & & & 0.756 & & & 0.359 & & & 0.710 & & & 0.721 & & \\
\hline
\end{tabular}

Note: $*$ significant at $1 \%, * *=$ significant at $5 \%,{ }^{\wedge}=$ significant at $10 \%$, Grt, age, inspection information is specific for each ship type 
Table 8 Type C Model Results - STCW, ILO

\begin{tabular}{|c|c|c|c|c|c|c|c|c|c|c|c|c|c|c|c|c|c|c|}
\hline \multirow[b]{2}{*}{ Variable } & \multicolumn{3}{|c|}{$\begin{array}{c}\text { C7: STCW } \\
\text { very serious }\end{array}$} & \multicolumn{3}{|c|}{$\begin{array}{l}\text { C8: STCW } \\
\text { serious }\end{array}$} & \multicolumn{3}{|c|}{$\begin{array}{l}\text { C9: STCW } \\
\text { less serious }\end{array}$} & \multicolumn{3}{|c|}{$\begin{array}{c}\text { C10: ILO } \\
\text { very serious }\end{array}$} & \multicolumn{3}{|c|}{$\begin{array}{l}\text { C11: ILO } \\
\text { serious }\end{array}$} & \multicolumn{3}{|c|}{$\begin{array}{c}\text { C12: ILO } \\
\text { less serious }\end{array}$} \\
\hline & Coeff & SE & & Coeff & SE & & Coeff & SE & & Coeff & SE & & Coeff & SE & & Coeff & SE & \\
\hline Intercept & 1.015 & 0.991 & & -1.138 & 1.054 & & -1.060 & 1.179 & & 1.217 & 1.069 & & 1.308 & 0.759 & & -1.090 & 0.855 & \\
\hline AGE & 0.025 & 0.019 & & 0.026 & 0.013 & $\wedge$ & -0.013 & 0.016 & & -0.008 & 0.015 & & -0.009 & 0.009 & & -0.032 & 0.010 & * \\
\hline GRT & -0.480 & 0.116 & $*$ & -0.174 & 0.091 & $\wedge$ & -0.034 & 0.088 & & -0.450 & 0.121 & $*$ & -0.208 & 0.086 & * & -0.022 & 0.087 & \\
\hline STCW 78 Convention & 1.180 & 0.457 & ** & 1.348 & 0.387 & * & 0.348 & 0.308 & & $\mathrm{n} / \mathrm{a}$ & $\mathrm{n} / \mathrm{a}$ & & $\mathrm{n} / \mathrm{a}$ & $\mathrm{n} / \mathrm{a}$ & & $\mathrm{n} / \mathrm{a}$ & $\mathrm{n} / \mathrm{a}$ & \\
\hline STCW 95 Amendment & 0.032 & 0.057 & & -0.026 & 0.060 & & -0.038 & 0.063 & & $\mathrm{n} / \mathrm{a}$ & $\mathrm{n} / \mathrm{a}$ & & $\mathrm{n} / \mathrm{a}$ & $\mathrm{n} / \mathrm{a}$ & & $\mathrm{n} / \mathrm{a}$ & $\mathrm{n} / \mathrm{a}$ & \\
\hline STCW White List & -0.252 & 0.106 & $* *$ & 0.098 & 0.119 & & 0.227 & 0.288 & & $\mathrm{n} / \mathrm{a}$ & $\mathrm{n} / \mathrm{a}$ & & $\mathrm{n} / \mathrm{a}$ & $\mathrm{n} / \mathrm{a}$ & & $\mathrm{n} / \mathrm{a}$ & $\mathrm{n} / \mathrm{a}$ & \\
\hline ILO 76 Convention & $\mathrm{n} / \mathrm{a}$ & $\mathrm{n} / \mathrm{a}$ & & $\mathrm{n} / \mathrm{a}$ & $\mathrm{n} / \mathrm{a}$ & & $\mathrm{n} / \mathrm{a}$ & $\mathrm{n} / \mathrm{a}$ & & 0.056 & 0.083 & & 0.001 & 0.095 & & -0.018 & 0.075 & \\
\hline ILO 96 Protocol & $\mathrm{n} / \mathrm{a}$ & $\mathrm{n} / \mathrm{a}$ & & $\mathrm{n} / \mathrm{a}$ & $\mathrm{n} / \mathrm{a}$ & & $\mathrm{n} / \mathrm{a}$ & $\mathrm{n} / \mathrm{a}$ & & 0.013 & 0.122 & & 0.029 & 0.105 & & -0.172 & 0.152 & \\
\hline Time to STWC 95 Amendment & -0.064 & 0.058 & & -0.053 & 0.059 & & -0.040 & 0.059 & & $\mathrm{n} / \mathrm{a}$ & $\mathrm{n} / \mathrm{a}$ & & $\mathrm{n} / \mathrm{a}$ & $\mathrm{n} / \mathrm{a}$ & & $\mathrm{n} / \mathrm{a}$ & $\mathrm{n} / \mathrm{a}$ & \\
\hline Time to ILO 96 Protocol & & & & & & & & & & -0.078 & 0.067 & & -0.044 & 0.052 & & -0.035 & 0.064 & \\
\hline Countries ratified STCW 78C & -0.283 & 0.112 & $* *$ & -0.361 & 0.100 & $*$ & -0.103 & 0.082 & & $\mathrm{n} / \mathrm{a}$ & $\mathrm{n} / \mathrm{a}$ & & $\mathrm{n} / \mathrm{a}$ & $\mathrm{n} / \mathrm{a}$ & & $\mathrm{n} / \mathrm{a}$ & $\mathrm{n} / \mathrm{a}$ & \\
\hline Countries ratified ILO 47C & $\mathrm{n} / \mathrm{a}$ & $\mathrm{n} / \mathrm{a}$ & & $\mathrm{n} / \mathrm{a}$ & $\mathrm{n} / \mathrm{a}$ & & $\mathrm{n} / \mathrm{a}$ & $\mathrm{n} / \mathrm{a}$ & & 0.061 & 0.087 & & -0.015 & 0.058 & & 0.022 & 0.034 & \\
\hline Countries ratified ILO 96P & $\mathrm{n} / \mathrm{a}$ & $\mathrm{n} / \mathrm{a}$ & & $\mathrm{n} / \mathrm{a}$ & $\mathrm{n} / \mathrm{a}$ & & $\mathrm{n} / \mathrm{a}$ & $\mathrm{n} / \mathrm{a}$ & & -0.178 & 0.061 & $*$ & 0.005 & 0.057 & & -0.061 & 0.118 & \\
\hline February & -0.235 & 0.071 & $*$ & -0.099 & 0.079 & & -0.136 & 0.081 & $\wedge$ & -0.258 & 0.073 & $*$ & -0.126 & 0.080 & & -0.171 & 0.073 & $* *$ \\
\hline March & -0.181 & 0.067 & $*$ & -0.084 & 0.068 & & 0.003 & 0.091 & & -0.214 & 0.070 & $*$ & -0.115 & 0.073 & & -0.033 & 0.081 & \\
\hline April & -0.272 & 0.078 & $*$ & -0.214 & 0.069 & $*$ & -0.094 & 0.082 & & -0.288 & 0.078 & $*$ & -0.229 & 0.070 & $*$ & -0.111 & 0.073 & \\
\hline May & -0.297 & 0.074 & $*$ & -0.305 & 0.071 & $*$ & -0.099 & 0.094 & & -0.324 & 0.070 & $*$ & -0.326 & 0.070 & * & -0.130 & 0.088 & \\
\hline June & -0.050 & 0.085 & & -0.196 & 0.071 & $*$ & -0.107 & 0.085 & & -0.079 & 0.070 & & -0.209 & 0.071 & $*$ & -0.137 & 0.072 & $\wedge$ \\
\hline July & -0.063 & 0.082 & & -0.011 & 0.072 & & 0.037 & 0.085 & & -0.081 & 0.078 & & -0.004 & 0.071 & & 0.006 & 0.073 & \\
\hline August & -0.256 & 0.091 & $*$ & -0.066 & 0.068 & & -0.112 & 0.096 & & -0.283 & 0.096 & $*$ & -0.074 & 0.069 & & -0.139 & 0.090 & \\
\hline September & -0.150 & 0.082 & $* *$ & -0.192 & 0.070 & * & -0.064 & 0.097 & & -0.170 & 0.079 & $* *$ & -0.200 & 0.069 & * & -0.094 & 0.087 & \\
\hline October & -0.101 & 0.086 & & -0.043 & 0.075 & & 0.031 & 0.088 & & -0.123 & 0.084 & $\wedge$ & -0.049 & 0.074 & & 0.001 & 0.077 & \\
\hline November & -0.056 & 0.088 & & -0.007 & 0.083 & & -0.034 & 0.094 & & -0.056 & 0.085 & & 0.006 & 0.084 & & -0.050 & 0.087 & \\
\hline December & 0.033 & 0.083 & & 0.021 & 0.061 & & 0.094 & 0.080 & & 0.010 & 0.084 & & 0.004 & 0.061 & & 0.063 & 0.075 & \\
\hline $\log (1+\mathrm{DV}) \mathrm{t}-1$ & 0.320 & 0.049 & $*$ & 0.475 & 0.059 & $*$ & 0.608 & 0.095 & * & 0.321 & 0.048 & $*$ & 0.509 & 0.055 & $*$ & 0.614 & 0.084 & $*$ \\
\hline $\log (1+\mathrm{DV}) \mathrm{t}-2$ & 0.296 & 0.048 & $*$ & 0.308 & 0.061 & $*$ & 0.092 & 0.110 & & 0.278 & 0.041 & $*$ & 0.367 & 0.057 & $*$ & 0.103 & 0.114 & \\
\hline Earnings & 0.063 & 0.045 & & 0.116 & 0.040 & $*$ & -0.046 & 0.049 & & 0.031 & 0.045 & & 0.014 & 0.037 & & -0.016 & 0.050 & \\
\hline PSC & 0.040 & 0.066 & & 0.093 & 0.064 & & -0.085 & 0.069 & & -0.090 & 0.051 & $\wedge$ & -0.064 & 0.082 & & -0.139 & 0.040 & $*$ \\
\hline Detentions & -0.070 & 0.018 & $*$ & 0.027 & 0.022 & & -0.042 & 0.065 & & -0.043 & 0.017 & $* *$ & 0.015 & 0.019 & & 0.048 & 0.043 & \\
\hline $\mathrm{R}^{2}$ of model & 0.848 & & & 0.856 & & & 0.767 & & & 0.845 & & & 0.849 & & & 0.770 & & \\
\hline
\end{tabular}

Note: $*=$ significant at $1 \%, * *=$ significant at $5 \%, \wedge=$ significant at $10 \%$ 
Table 9 presents the type D combination models where we measure the effect of legislation and ratification on casualty types. Since we already took collisions and contacts into account with the COLREG convention and loss of life with SAR, we concentrate on fire and explosions and machinery related failures. Notwithstanding the models for the TONNAGE and LOADLINE convention were we also use hull related failures, we reuse this type of dependent variable and also present individual results for tankers and dry bulk carriers. We further combine relevant SOLAS and MARPOL measures when appropriate, especially for fire and explosions and for hull related issues with tankers.

The results for fire and explosion clearly indicate that the entry into force of SOLAS 74 had a decreasing effect on this type of casualty as well as the IBC code. Similar as with the type A models, the number of countries which had ratified SOLAS 74 presents a positive effect. For the SOLAS 88 Protocol and for MARPOL Annex III, this is not the case where ratification matters rather than the actual entry into force. Most relevant amendments for SOLAS show a positive immediate effect including the SOLAS 81 Amendment which introduced a revised chapter on fire safety requirements on cargo ship and the SOLAS 96 Amendments which modified Chapter II of SOLAS and made the International Code for Application of Fire Test Procedures mandatory. For tankers, the picture slightly changes and only the ISM code including the time to entry into force shows a decreasing effect besides the IBC Code. The SOLAS 78 Protocol which introduced inert gas or other SOLAS amendments is not significant.

Seasonality is not very strong for fire and explosions and machinery related failures but is much stronger for the hull related failures for tankers and dry bulk carriers where January is the worst month. For hull related failures on tankers, only the SOLAS 94 and 95 amendment shows a negative effect which are not directly related to hull related issues while Annex I gives a positive effect while the number of countries who had ratified the convention present is negative. The same applies for the time to entry into force of the SOLAS 97 amendment which is dealing with safety related issued. Finally, time to entry into force of the phase out of the singly hull tankers clearly decreased the number of hull related failures with tankers.

For dry bulk carriers, none of the measures for additional safety for bulk carriers come out to be significant; however the entry into force of the ISM code including time to entry into force does show a decreasing effect on hull related failures. The same applies for ratification of the SOLAS 78 Protocol. With respect to machinery related failures on all ships, again the ISM code and the SOLAS 02 Amendments gives a decreasing effect, the latter included new measures for machinery and electrical installations as well as fire protection and life saving appliances.

In summary, the type D models indicate that overall, some decreasing effects of the legislative framework can be found with respect to fire and explosions, hull related and machinery related casualties where sometimes the effect is associated with the timing of entry into force and sometimes, it is associated with ratification. Seasonality is strongest with hull related failures and not very significant for fire and explosions and machinery failures. 
Table 9 Type D Model Results - Fire \& Explosion, Hull and Machinery related failures

\begin{tabular}{|c|c|c|c|c|c|c|c|c|c|c|c|c|c|c|c|}
\hline \multirow[b]{2}{*}{ Variable } & \multicolumn{3}{|c|}{$\begin{array}{c}\text { D1: Fire \& Explosion } \\
\text { all ships }\end{array}$} & \multicolumn{3}{|c|}{$\begin{array}{c}\text { D2: Fire \& Explosion } \\
\text { tanker }\end{array}$} & \multicolumn{3}{|c|}{$\begin{array}{c}\text { D3: Hull related failures } \\
\text { tanker }\end{array}$} & \multicolumn{3}{|c|}{$\begin{array}{l}\text { D4: Hull related } \\
\text { failures, dry bulk }\end{array}$} & \multicolumn{3}{|c|}{$\begin{array}{l}\text { D5: Machinery related } \\
\text { failures all ships }\end{array}$} \\
\hline & Coeff & SE & & Coeff & SE & & Coeff & SE & & Coeff & SE & & Coeff & SE & \\
\hline & -8.461 & 1.784 & & -12.406 & 1.858 & & -11.275 & 1.376 & & -8.808 & 1.865 & & -4.430 & 1.153 & \\
\hline AGE & 0.020 & 0.023 & & -0.005 & 0.016 & & 0.016 & 0.011 & & 0.025 & 0.011 & $* *$ & -0.006 & 0.013 & \\
\hline GRT & -0.438 & 0.148 & $*$ & 0.008 & 0.114 & & 0.193 & 0.099 & $\wedge$ & -0.090 & 0.148 & & -0.146 & 0.088 & $\wedge$ \\
\hline SOL-74 Convention & -7.101 & 3.867 & $\wedge$ & -3.449 & 5.395 & & -2.516 & 3.356 & & -5.344 & 3.424 & & -2.134 & 1.825 & \\
\hline SOL-78 Protocol (inert gas) & 1.981 & 2.250 & & 1.827 & 3.117 & & -1.811 & 2.105 & & 6.088 & 2.010 & * & 1.687 & 1.013 & $\wedge$ \\
\hline SOL-81 Amendment (fire measures) & 0.093 & 0.220 & & -0.270 & 0.315 & & -0.046 & 0.256 & & 0.467 & 0.270 & $\wedge$ & 0.101 & 0.145 & \\
\hline SOL-88 Protocol (HSSC) & 4.234 & 2.349 & $\wedge$ & 4.107 & 3.648 & & 1.421 & 2.176 & & 1.985 & 1.221 & & -0.403 & 0.568 & \\
\hline SOL-88 Amendment (GMDSS) & $\mathrm{n} / \mathrm{a}$ & $\mathrm{n} / \mathrm{a}$ & & $\mathrm{n} / \mathrm{a}$ & $\mathrm{n} / \mathrm{a}$ & & -0.215 & 0.183 & & -0.073 & 0.131 & & -0.084 & 0.077 & \\
\hline SOL-93 Amendment (ISM) & 0.179 & 0.183 & & -0.938 & 0.247 & $*$ & 0.079 & 0.146 & & -0.360 & 0.173 & ** & -0.244 & 0.103 & ** \\
\hline SOL-94 Amendment (ESP) & $\mathrm{n} / \mathrm{a}$ & $\mathrm{n} / \mathrm{a}$ & & $\mathrm{n} / \mathrm{a}$ & $\mathrm{n} / \mathrm{a}$ & & 0.078 & 0.079 & & 0.237 & 0.150 & & -0.102 & 0.090 & \\
\hline SOL-95 Amendment (damage stability) & $\mathrm{n} / \mathrm{a}$ & $\mathrm{n} / \mathrm{a}$ & & $\mathrm{n} / \mathrm{a}$ & $\mathrm{n} / \mathrm{a}$ & & -0.332 & 0.136 & $* *$ & 0.141 & 0.097 & & 0.114 & 0.059 & $\wedge$ \\
\hline SOL-96 Amendment (LSA, Fire testing) & 0.394 & 0.131 & * & 0.128 & 0.166 & & -0.221 & 0.119 & $\wedge$ & 0.350 & 0.144 & $* *$ & -0.020 & 0.081 & \\
\hline SOL-97 Amendment (add safety, bulk) & $\mathrm{n} / \mathrm{a}$ & $\mathrm{n} / \mathrm{a}$ & & $\mathrm{n} / \mathrm{a}$ & $\mathrm{n} / \mathrm{a}$ & & -0.160 & 0.127 & & 0.006 & 0.137 & & 0.070 & 0.087 & \\
\hline SOL-02 Amendment (safety, machinery, fire, LSA) & -0.138 & 0.182 & & -0.129 & 0.247 & & -0.026 & 0.203 & & 0.037 & 0.199 & & -0.280 & 0.102 & $*$ \\
\hline SOL-04 Amendment (add. safety, bulk) & $\mathrm{n} / \mathrm{a}$ & $\mathrm{n} / \mathrm{a}$ & & $\mathrm{n} / \mathrm{a}$ & $\mathrm{n} / \mathrm{a}$ & & 0.143 & 0.132 & & 0.010 & 0.130 & & 0.054 & 0.076 & \\
\hline MAR-Annex I (oil) & 0.069 & 1.198 & & -2.149 & 2.076 & & 2.188 & 1.313 & $\wedge$ & $\mathrm{n} / \mathrm{a}$ & $\mathrm{n} / \mathrm{a}$ & & $\mathrm{n} / \mathrm{a}$ & $\mathrm{n} / \mathrm{a}$ & \\
\hline MAR-Annex III (packaged substances) & 5.444 & 1.734 & $*$ & $\mathrm{n} / \mathrm{a}$ & $\mathrm{n} / \mathrm{a}$ & & $\mathrm{n} / \mathrm{a}$ & $\mathrm{n} / \mathrm{a}$ & & $\mathrm{n} / \mathrm{a}$ & $\mathrm{n} / \mathrm{a}$ & & $\mathrm{n} / \mathrm{a}$ & $\mathrm{n} / \mathrm{a}$ & \\
\hline IBC Code mandatory (chemicals) & -0.597 & 0.141 & $*$ & -0.612 & 0.221 & * & -0.041 & 0.143 & & $\mathrm{n} / \mathrm{a}$ & $\mathrm{n} / \mathrm{a}$ & & $\mathrm{n} / \mathrm{a}$ & $\mathrm{n} / \mathrm{a}$ & \\
\hline MAR-01 Amendment (CAS, phase out) & 0.484 & 0.244 & $* *$ & 0.217 & 0.331 & & 0.195 & 0.238 & & $\mathrm{n} / \mathrm{a}$ & $\mathrm{n} / \mathrm{a}$ & & $\mathrm{n} / \mathrm{a}$ & $\mathrm{n} / \mathrm{a}$ & \\
\hline MAR-03 Amendment (revised phase out) & 0.379 & 0.239 & & 0.546 & 0.216 & $* *$ & -0.069 & 0.239 & & $\mathrm{n} / \mathrm{a}$ & $\mathrm{n} / \mathrm{a}$ & & $\mathrm{n} / \mathrm{a}$ & $\mathrm{n} / \mathrm{a}$ & \\
\hline Time to 81 SOL Amend. & 0.364 & 0.177 & $* *$ & -0.005 & 0.266 & & 0.198 & 0.192 & & 0.274 & 0.238 & & 0.095 & 0.097 & \\
\hline Time to 97 SOL Amend. & $\mathrm{n} / \mathrm{a}$ & $\mathrm{n} / \mathrm{a}$ & & $\mathrm{n} / \mathrm{a}$ & $\mathrm{n} / \mathrm{a}$ & & 0.245 & 0.116 & $* *$ & 0.059 & 0.090 & & -0.008 & 0.058 & \\
\hline Time to 93 SOL Amend. & 0.112 & 0.123 & & -0.570 & 0.187 & $*$ & 0.048 & 0.116 & & -0.138 & 0.101 & & -0.240 & 0.092 & $*$ \\
\hline Time to 01 MAR Amend. & 0.549 & 0.197 & $*$ & 0.214 & 0.427 & & 0.038 & 0.167 & & $\mathrm{n} / \mathrm{a}$ & $\mathrm{n} / \mathrm{a}$ & & $\mathrm{n} / \mathrm{a}$ & $\mathrm{n} / \mathrm{a}$ & \\
\hline Time to 03 MAR Amend. & 0.045 & 0.161 & & 0.486 & 0.384 & & -0.388 & 0.156 & $* *$ & $\mathrm{n} / \mathrm{a}$ & $\mathrm{n} / \mathrm{a}$ & & $\mathrm{n} / \mathrm{a}$ & $\mathrm{n} / \mathrm{a}$ & \\
\hline Countries ratified 74 Conv. & 1.898 & 1.016 & $\wedge$ & 0.890 & 1.427 & & 0.688 & 0.885 & & 1.463 & 0.903 & & 0.568 & 0.478 & \\
\hline Countries ratified 78 Prot. & -0.691 & 0.778 & & -0.509 & 1.082 & & 0.455 & 0.741 & & -2.077 & 0.705 & * & -0.549 & 0.358 & \\
\hline Countries ratified 88 Prot. & -1.055 & 0.628 & $\wedge$ & -1.143 & 0.975 & & -0.368 & 0.572 & & -0.483 & 0.309 & & 0.160 & 0.147 & \\
\hline Countries ratified Annex I & -0.137 & 0.414 & & 0.596 & 0.708 & & -0.723 & 0.427 & $\wedge$ & $\mathrm{n} / \mathrm{a}$ & $\mathrm{n} / \mathrm{a}$ & & $\mathrm{n} / \mathrm{a}$ & $\mathrm{n} / \mathrm{a}$ & \\
\hline Countries ratified Annex III & -1.408 & 0.430 & $*$ & $\mathrm{n} / \mathrm{a}$ & $\mathrm{n} / \mathrm{a}$ & & $\mathrm{n} / \mathrm{a}$ & $\mathrm{n} / \mathrm{a}$ & & $\mathrm{n} / \mathrm{a}$ & $\mathrm{n} / \mathrm{a}$ & & $\mathrm{n} / \mathrm{a}$ & $\mathrm{n} / \mathrm{a}$ & \\
\hline
\end{tabular}




\begin{tabular}{|c|c|c|c|c|c|c|c|c|c|c|c|c|c|c|c|}
\hline \multirow{2}{*}{$\begin{array}{l}\text { Table } 9 \text { continued } \\
\text { February }\end{array}$} & \multicolumn{3}{|c|}{$\begin{array}{c}\text { Fire \& Explosion } \\
\text { all ships }\end{array}$} & \multicolumn{3}{|c|}{$\begin{array}{c}\text { Fire \& Explosion } \\
\text { tanker }\end{array}$} & \multicolumn{3}{|c|}{$\begin{array}{c}\text { Hull related failures } \\
\text { tanker }\end{array}$} & \multicolumn{3}{|c|}{$\begin{array}{c}\text { Hull related failures } \\
\text { dry bulk }\end{array}$} & \multicolumn{3}{|c|}{$\begin{array}{l}\text { Machinery related } \\
\text { failures all ships }\end{array}$} \\
\hline & 0.089 & 0.069 & & 0.072 & 0.111 & & -0.201 & 0.082 & $* *$ & -0.310 & 0.102 & $*$ & -0.080 & 0.071 & \\
\hline March & 0.026 & 0.070 & & 0.088 & 0.102 & & -0.242 & 0.074 & $*$ & -0.136 & 0.101 & & -0.043 & 0.072 & \\
\hline April & -0.104 & 0.083 & & -0.101 & 0.120 & & -0.285 & 0.076 & $*$ & -0.279 & 0.099 & * & -0.135 & 0.079 & $\wedge$ \\
\hline May & -0.161 & 0.105 & & -0.013 & 0.139 & & -0.528 & 0.075 & * & -0.433 & 0.128 & $*$ & -0.176 & 0.071 & ** \\
\hline June & -0.190 & 0.093 & $* *$ & -0.032 & 0.139 & & -0.508 & 0.089 & $*$ & -0.226 & 0.117 & $\wedge$ & -0.151 & 0.073 & $* *$ \\
\hline July & -0.027 & 0.075 & & 0.115 & 0.122 & & -0.387 & 0.095 & * & -0.416 & 0.111 & * & -0.031 & 0.069 & \\
\hline August & -0.056 & 0.078 & & -0.064 & 0.119 & & -0.419 & 0.074 & $*$ & -0.393 & 0.122 & $*$ & -0.138 & 0.073 & $\wedge$ \\
\hline September & -0.239 & 0.087 & $* *$ & -0.025 & 0.134 & & -0.249 & 0.096 & * & -0.251 & 0.098 & $* *$ & -0.123 & 0.085 & \\
\hline October & -0.091 & 0.075 & & -0.050 & 0.138 & & -0.198 & 0.075 & $*$ & -0.282 & 0.100 & $*$ & -0.080 & 0.071 & \\
\hline November & -0.167 & 0.083 & $* *$ & 0.106 & 0.129 & & -0.270 & 0.080 & $*$ & -0.220 & 0.126 & & -0.056 & 0.084 & \\
\hline December & -0.014 & 0.079 & & 0.006 & 0.122 & & 0.021 & 0.082 & & -0.038 & 0.113 & & 0.017 & 0.073 & \\
\hline $\log (1+D V) t-1$ & -0.004 & 0.048 & & 0.038 & 0.066 & & -0.027 & 0.056 & & 0.174 & 0.060 & $*$ & 0.326 & 0.055 & * \\
\hline $\log (1+D V) t-2$ & 0.039 & 0.049 & & -0.088 & 0.053 & $\wedge$ & -0.035 & 0.051 & & 0.116 & 0.052 & $* *$ & 0.091 & 0.077 & \\
\hline Earnings & 0.488 & 0.116 & $*$ & 0.266 & 0.093 & $*$ & 0.072 & 0.060 & & 0.382 & 0.133 & $*$ & 0.177 & 0.060 & $*$ \\
\hline PSC & -0.128 & 0.184 & & -0.048 & 0.248 & & -0.417 & 0.163 & $* *$ & 0.632 & 0.279 & $* *$ & 0.090 & 0.071 & \\
\hline Detentions & -0.045 & 0.034 & & -0.047 & 0.110 & & -0.006 & 0.085 & & -0.018 & 0.056 & & -0.021 & 0.026 & \\
\hline $\mathrm{R}^{2}$ of model & 0.535 & & & 0.424 & & & 0.771 & & & 0.417 & & & 0.641 & & \\
\hline
\end{tabular}

Note: $*=$ significant at $1 \%, * *=$ significant at $5 \%, \wedge=$ significant at $10 \%$, grt, age, inspection information is specific for each ship type 


\section{Conclusions and recommendations on policy implications}

In this article, we made a first attempt and presented econometric models to measure the effectiveness of international conventions and relevant amendments. We based our analysis on 45 milestones of the legislative framework and corrected for other factors which can influence safety such as ship economic cycles, safety inspections and other unilateral legislation. We also measured the effect of ratification of a convention by taking the number of parties into account. Finally, we accounted for the time of adoption to the time of entry into force of relevant measures. This final section presents a global summary of the main findings of the models and tries to identify areas of weaknesses in the legislative framework. Finally, we also present our recommendations to the policy makers.

\subsection{Summary of main findings per convention}

For the SOLAS models, the effect of entry into force shows a negative relationship for very serious and serious casualties, especially for dry bulk carriers. The implementation of the ISM code including the time from adoption to entry into force decreased all types of casualties, especially for dry bulk carriers and general cargo vessels. Other amendments which show a negative effect are GMDSS and the SOLAS 02 and 04 Amendments (enhanced bulk carrier safety, freefall lifeboats, additional measures for fire protection and life saving appliances). However, the number of countries which had ratified the convention is mainly not significant which could be explained by the fact that SOLAS is the main convention of IMO and many countries have ratified the convention. In addition, some of the amendments of SOLAS such as the 78 and 88 Protocol, ESP and LSA are not significant or show a positive effect.

The MARPOL models indicate that the various amendments in relation with the phase out of single hull tankers and CAS decreased the number of casualties with pollution and to a certain degree also the amount of pollution. The effect of MARPOL Annex III cannot be measures but the number of countries who had ratified the convention shows a decreasing effect. Furthermore, the IBC code decreased casualties with relation to fire and explosion on tankers.

For the LOADLINE, TONNAGE, the SAR and STCW convention, the number of countries which ratified the convention indicates improvement rather than the entry into force of the convention itself. For STCW, the introduction of the STCW White List further decreased the number of very serious casualties. We cannot measure the effect of COLREG which might be due to the fact that the convention came into force very early in our time frame for the analysis. Some disappointing results can be associated with the ILO convention where we cannot measure the effect of entry into force nor the number of countries which had ratified it. However, the effect of the ILO 96 Protocol presents a decreasing effect for very serious casualties.

Our results also show that seasonality matters and that January is the worth month, be it with the various types of seriousness of casualties or the loss of life. We can observe less seasonality with respect to MARPOL and fire and explosions. This is not surprisingly since casualties of a technical nature (hull integrity, flooding, foundering, wrecked, etc.) are more prone to the effects of weather while pollution related casualties and fire and explosion are more influenced by operational issues which are less dependent on the weather. 


\subsection{Overall evaluation and recommendations on policy implications}

In order to provide a higher level evaluation of the legislative framework, we look at two aspects in aggregated format as follows: 1) the number of countries that had ratified a convention and 2) the legislative measures identified in the milestones and grouped into areas such as technical areas, pollution, search \& rescue, safety management and human related areas such as living and working conditions and certification. For both areas, we count the effects of all 29 models and distinguish between three possible outcomes: 1) positive effects, 2) negative effects (which mean less accidents and pollution) and 3) effects which could not be measured.

For the number of countries which had ratified a convention, we have 65 possible outcomes of which 21 are significant (32\%). Of the significant variables, 16 show negative effects and 5 a positive effect. We conclude that overall, the number or countries that have ratified a convention is associated with a negative effect on accidents and pollution but that overall, the results also indicate that there is a certain degree of enforcement. At the moment, the only means of measuring the lack of enforcement at IMO level is in aggregated format and not by identifying flags which do have a problem in enforcing legislation.

Given the negative effect which was associated with the "STCW White list", a policy implication for this finding could be that it might be beneficial for IMO to create similar lists for other conventions and indicate the level of enforcement of its member states. This could be measured by using for instance casualty data or port state control data from all regional regimes and by creating performance indicators for flag states which could be published yearly following the same idea as the STCW White list.

For the second area dealing with the entry into force of certain measures, aggregation of the results is a bit more complex but the same approach is taken. Out of the total 29 models, we have 260 possible outcomes which are grouped into effects that are positive, negative and effects which cannot be measured. Out of the 260 outcomes, we have 87 that are significant (33\%) and 45 which show a negative effect. The variables are then grouped into the areas mentioned in the beginning of this section and the result is presented in Figure 1 below for all model types and in Figure 2 based on the models using the seriousness of a casualty as dependent variable.

Figure 1: Effect of legislation per area based on all model types

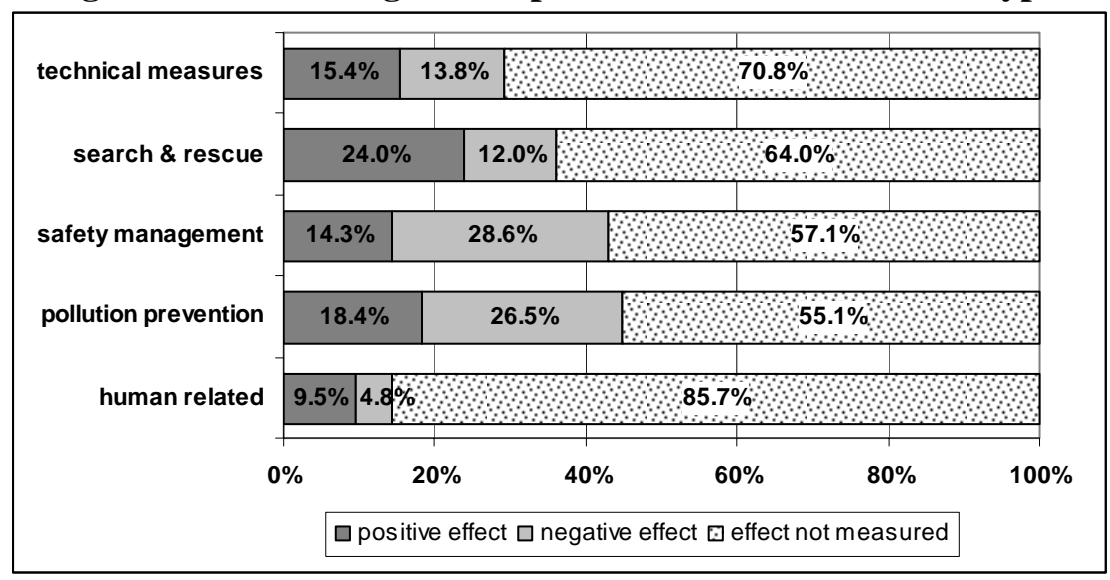

As indicated previously, the classification of seriousness of casualty can be considered as the most reliable classification and we therefore also present the results based on the models 
where seriousness of casualty was used as dependent variable compared to all types of casualties (e.g. casualty first events such as hull related or machinery related casualties or casualties per ship type irrespective of seriousness). This means, we exclude all other models with the exception of the SAR model (lives lost).

The results in Figure 1 indicate that most of the negative effect on incidents can be measured in areas related to safety management and pollution prevention while human related areas which are associated with working and living conditions and certification only present a small amount of negative effects. The results in Figure 2 now show stronger effects which can be measured in all areas but still presents the strongest effect associated with safety management and pollution prevention. Human related measures are still weak in impact.

Figure 2: Effect of legislation per area based on seriousness

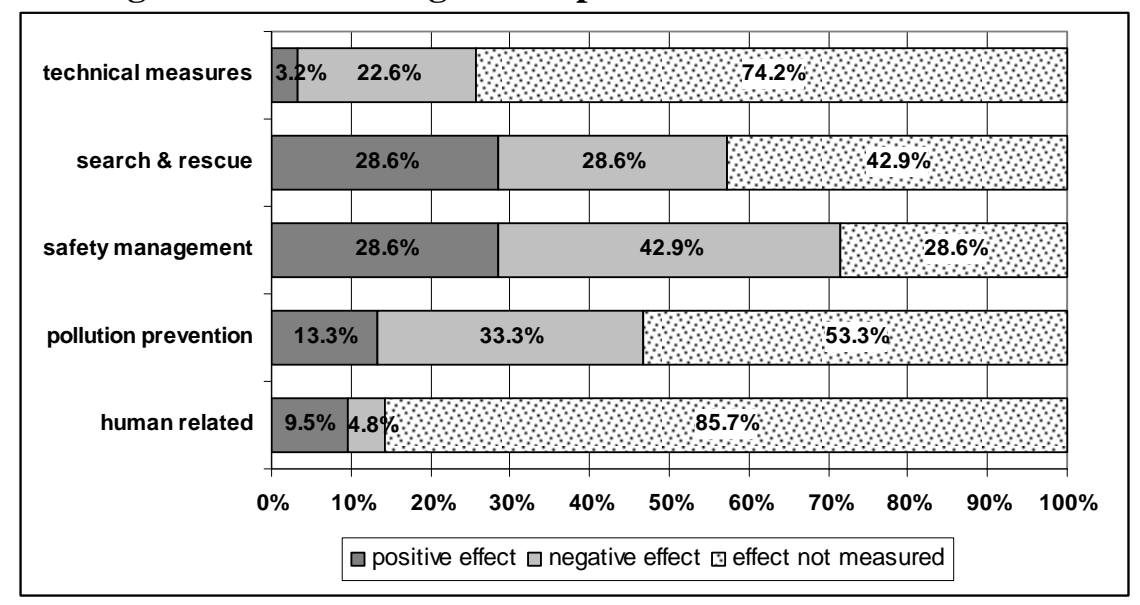

We obtain surprising results with respect to the technical areas where one would expect to find a stronger decreasing effect and especially as the shipping industry has always put more emphasis on the technical side of ships. This attitude is slowly changing as the implementation of the ISM code, which increased the awareness of safety management and its effect, is reflected by the negative effect of the legislation in this area shown in Figure 1 and 2.

The ISM code however does not necessarily contribute towards enhancing the living and working conditions of the crew. The various ILO conventions recently benefited from a major overhaul of the legislative framework ending in the adoption of the 2006 Maritime Labor Convention. Tentative entry into force date is set for 2010 or 2011. Our immediate policy implication is to support the new convention and to place more emphasis on the well being of the crew.

Another policy implication and recommendation for the findings with respect to the seasonality aspects where more casualties can be found in the winter month is to improve crew training in general and also to improve the situation of fatigue associated with bad weather conditions. Perhaps minimum safety manning standards could be changed for the winter months so that the crew can get more resting periods. This recommendation also goes in line with the general findings of the ILO convention.

As policy implication for the results of some of the positive effects associated with the technical areas primarily given by the SOLAS models, one could conclude that the positive effects indicate the fact that legislation follows after a major disaster and that by the time it 
come into force, the effect cannot be measured immediately since the number of casualties is still high. It is therefore important for IMO to shifts its emphasis to preventive measures such as the Formal Safety Assessment framework so that risk can be identified before hand and action be taken accordingly. In order to use FSA for legislative measures, a common database should be developed with common classifications of casualty first events and the combination of data sources from commercial data providers and IMO. Another aspect would be to improve the population of data with respect to pollution such as oil or chemicals.

\subsection{Future research}

Finally, we would like to suggest areas for further research. This article used time series of monthly totals or averages for the time period 1977 to 2007. The models therefore do not measure the effect of legislation at an individual ship level which would be a further area for investigation if more data becomes available and if the classification of casualties is improved throughout the industry. If measured at a ship level, the individual effects of the flags could also be included so as to identify weak areas of enforcement irrespective from ratification. We also believe that a similar analysis could be performed for SOLAS, MARPOL and ILO (once the new convention has entered into force) every five years in order to continue measuring the effect of new amendments.

\section{References}

[1] Goulielmos AM and Giziakis K, 1998, Treatment of uncompensated cost of marine accidents in a model of welfare economics, Disaster Prevention and Management, Volume 7, Number 3, pp 183-187

[2] Assembly Resolution A.989(25), Strategic Plan for the Organization (for the six-year period 2008-2013), adopted $20^{\text {th }}$ November 2007, IMO, London

[3] Assembly Resolution A.990(25), High Level Action Plan of the Organization and Priorities for the 2008-2009 biennium, adopted $29^{\text {th }}$ November 2007, IMO, London

[4] Oran R. Young, The Effectiveness of International Environmental Regimes: Causal Connections and Behavioral Mechanisms, Cambridge, MA: MIT Press, 1999

[5] E. Eliopoulou and A. Papanikolaou, Casualty analysis of large tankers, J Mar Sci Technol (2007), 12:240-250

[6] S. Delautre, E. Eliopoulou and N. Mikelis, The Influence of Regulations on the Safety Record of the Aframax Tankers, Working Paper of the POPC project

[7] Bijwaard G and Knapp S, Analysis of Ship Life Cycles - The Impact of Economic Cycles and Ship Inspections, Marine Policy 2009, volume 33, pp. 350-369

[8] Ronald B. Michel, Regime Design Matters: Intentional Oil Pollution and Treaty Compliance, International Organization, Volume 48, Issue 3 (Summer, 1994), 425-458 
[9] MSC/Circ. 953, MEPC/Circ. 372, Reports on Marine Casualties and Incidents, Revised harmonized reporting procedures, adopted $14^{\text {th }}$ December 2000, IMO, London

[10] MSC Resolution MSC.255(84), Casualty Investigation Code, adopted 16 May 2008, IMO, London

[11] Status of Multilateral Conventions and Instruments in respect of which the International Maritime Organization or its Secretary General performs depositary or other functions, December 2007, IMO, London, www.imo.org

[12] IMO, MSC 82/INF.11, Implementation of Instruments and related matters, Note by the secretariat, 6 October 2006

[13] Knapp S, Franses PH, Comprehensive Review of the Maritime Safety Regimes - Present Status and Recommendations on improvement, Econometric Institute Report

2007-Nr. 19: http://repub.eur.nl/publications/index/888058212/

[14] Heij C., De Boer P., Franses, PH, Kloek T. and van Dijk, HK, Econometric Methods with Applications in Business and Economics, Oxford University Press, New York, 2004 
Appendix 1: Development of the legislative framework in shipping

\begin{tabular}{|c|c|c|c|c|c|c|c|c|}
\hline ST & $\begin{array}{l}\text { Main Events } \\
\text { influencing safety }\end{array}$ & $\begin{array}{l}\text { Damage/ } \\
\text { in response to }\end{array}$ & $\begin{array}{l}\text { Event } \\
\text { year }\end{array}$ & $\begin{array}{r}\text { Adoption } \\
\text { date }\end{array}$ & $\begin{array}{l}\text { Entry into } \\
\text { force date }\end{array}$ & Time & MS & Detail of event or legal instrument \\
\hline pax & Titanic & 1517 lost & 1912 & $\mathrm{n} / \mathrm{a}$ & $\mathrm{n} / \mathrm{a}$ & $\mathrm{n} / \mathrm{a}$ & $\mathrm{A}$ & famous passenger liner accident, North Atlantic \\
\hline all & ILO C7 (Min Age) & & 1920 & 09/07/1920 & $27 / 09 / 1921$ & 1.2 & $\mathrm{~N}$ & Minimum Age Sea Convention \\
\hline all & ILO C8 (Unemployment) & & 1920 & 09/07/1920 & $16 / 03 / 1923$ & 2.7 & $\mathrm{~N}$ & Unemployment Indemnity (Shipwreck) \\
\hline all & ILO C9 (Placing of Seam) & & 1920 & $10 / 07 / 1920$ & 23/11/1921 & 1.4 & $\mathrm{~N}$ & Placing of Seaman Convention \\
\hline all & Conv. establishing IMO & & 1948 & 06/03/1948 & $17 / 03 / 1958$ & 10.0 & $\mathrm{~N}$ & Conventions establishing IMO \\
\hline all & LOAD LINES 66 & & 1966 & 05/04/1966 & $21 / 07 / 1968$ & 2.3 & $\mathrm{Y}$ & regulated load line, strength of hull, freeboard allowance \\
\hline $\operatorname{tank}$ & Torrey Canyon & 119,000 tons & 1968 & $\mathrm{n} / \mathrm{a}$ & $\mathrm{n} / \mathrm{a}$ & $\mathrm{n} / \mathrm{a}$ & $\mathrm{A}$ & large tanker accident, coast of England \\
\hline & IACS starts operation & & 1968 & $11 / 09 / 1968$ & $\mathrm{n} / \mathrm{a}$ & $\mathrm{n} / \mathrm{a}$ & $\mathrm{Y}$ & IACS starts with 7 members \\
\hline all & Tonnage Convention & & 1969 & 23/06/1969 & $18 / 07 / 1982$ & 13.5 & $\mathrm{~N}$ & Intern. Convention on Tonnage Measurement of ships \\
\hline all & CLC Convention & Torrey Canyon & 1969 & $\mathrm{n} / \mathrm{a}$ & $\mathrm{n} / \mathrm{a}$ & $\mathrm{n} / \mathrm{a}$ & $\mathrm{N}$ & Convention related to civil liability for oil pollution damage \\
\hline all & COLREG 72 & & 1972 & $20 / 10 / 1972$ & $15 / 07 / 1977$ & 4.7 & $\mathrm{Y}$ & regulates collision regulations \\
\hline tank & Metula & 47,000 tons & 1974 & $\mathrm{n} / \mathrm{a}$ & $\mathrm{n} / \mathrm{a}$ & $\mathrm{n} / \mathrm{a}$ & $\mathrm{A}$ & large tanker accident, Magellan Street, Chile \\
\hline all & SOLAS 74 & Titanic & 1974 & $01 / 11 / 1974$ & $25 / 05 / 1980$ & 5.6 & $\mathrm{Y}$ & regulates technical aspects of safety \\
\hline all & ILO147 MinSt 1976 & & 1976 & 29/10/1976 & 28/11/1981 & 5.1 & $\mathrm{Y}$ & improve working and living conditions \\
\hline $\operatorname{tank}$ & Argo Merchant & 28,000 tons & 1976 & $\mathrm{n} / \mathrm{a}$ & $\mathrm{n} / \mathrm{a}$ & $\mathrm{n} / \mathrm{a}$ & A & large tanker accident, Nantucket Sound, USA \\
\hline all & MARPOL 73/78 ANNEX I & Torrey Canyon & 1978 & $17 / 02 / 1978$ & $02 / 10 / 1983$ & 5.6 & $\mathrm{Y}$ & oil pollution, SBT, COW \\
\hline all & MARPOL 73/78 ANNEX II & Torrey Canyon & 1978 & $17 / 02 / 1978$ & $06 / 04 / 1987$ & 9.1 & $\mathrm{Y}$ & harmful substances in liquid form (NLS) \\
\hline all & MARPOL 73/78 ANNEX III & & 1978 & $17 / 02 / 1978$ & 01/07/1992 & $\mathrm{n} / \mathrm{a}$ & $\mathrm{Y}$ & harmful substances in packaged form \\
\hline all & MARPOL 73/78 ANNEX IV & & 1978 & $17 / 02 / 1978$ & $27 / 09 / 2003$ & $\mathrm{n} / \mathrm{a}$ & $\mathrm{Y}$ & sewage \\
\hline all & MARPOL 73/78 ANNEX V & & 1978 & $17 / 02 / 1978$ & $31 / 12 / 1988$ & $\mathrm{n} / \mathrm{a}$ & Y & garbage \\
\hline all & SOLASProt78 & & 1978 & $17 / 02 / 1978$ & 01/05/1981 & 3.2 & $\mathrm{Y}$ & inert gas, two radars, remote steering gear, power units \\
\hline tank & Amoco Cadiz & 223,000 tons & 1978 & $\mathrm{n} / \mathrm{a}$ & $\mathrm{n} / \mathrm{a}$ & $\mathrm{n} / \mathrm{a}$ & $\mathrm{A}$ & large tanker accident, coast of France \\
\hline all & STCW 78 & & 1978 & 07/07/1978 & $28 / 04 / 1984$ & 5.8 & $\mathrm{Y}$ & to improve quality of seafarers (training, certification \& watchkeeping) \\
\hline all & SARConvention & & 1979 & 27/04/1979 & $22 / 06 / 1985$ & 6.2 & $\mathrm{Y}$ & help reducing number of victims (search and rescue) \\
\hline tank & Atlantic Empress & 287,000 tons & 1979 & $\mathrm{n} / \mathrm{a}$ & $\mathrm{n} / \mathrm{a}$ & $\mathrm{n} / \mathrm{a}$ & $\mathrm{A}$ & large tanker accident, coast of Trinidad \& Tobago \\
\hline bulk & Derbyshire & 42 lost & 1980 & $\mathrm{n} / \mathrm{a}$ & $\mathrm{n} / \mathrm{a}$ & $\mathrm{n} / \mathrm{a}$ & $\mathrm{A}$ & large dry bulk carrier sunk, Japan \\
\hline all & SOLAS81-11Amend. & Amoco Cadiz & 1981 & $20 / 11 / 1981$ & $01 / 09 / 1984$ & 2.8 & $\mathrm{Y}$ & fire safety, machinery and electrical installations \\
\hline all & Paris MoU starts & Amoco Cadiz & 1982 & 26/01/1982 & $01 / 07 / 1982$ & 0.4 & Y & PSC inspections mainly Europe \\
\hline $\operatorname{tank}$ & SOLAS83Amend. & & 1983 & $17 / 06 / 1983$ & 01/07/1986 & 3.0 & $\mathrm{~N}$ & IBC Code and IGC Code mandatory \\
\hline tank & Castillo de Bellver & 252,000 tons & 1983 & $\mathrm{n} / \mathrm{a}$ & $\mathrm{n} / \mathrm{a}$ & $\mathrm{n} / \mathrm{a}$ & $\mathrm{A}$ & large tanker accident, South Africa \\
\hline pax & Herald of Free Enterprise & 193 lost & 1987 & $\mathrm{n} / \mathrm{a}$ & $\mathrm{n} / \mathrm{a}$ & $\mathrm{n} / \mathrm{a}$ & $\mathrm{A}$ & major ferry accident, coast of Belgium \\
\hline pax & Dona Pax & 4000 lost & 1987 & $\mathrm{n} / \mathrm{a}$ & $\mathrm{n} / \mathrm{a}$ & $\mathrm{n} / \mathrm{a}$ & $\mathrm{A}$ & major ferry accident, Philippines \\
\hline pax & SOLAS88-04Amend & Herald of FE & 1988 & $21 / 04 / 1988$ & $22 / 10 / 1989$ & 1.5 & $\mathrm{~N}$ & improved doors, emergency steering gear and lighting \\
\hline all & SOLAS88-10Amend & Herald of FE & 1988 & 28/10/1988 & 29/04/1990 & 1.5 & $\mathrm{~N}$ & compulsory lightweight surveys for pax vessels, stability of damage conditions \\
\hline all & SOLAS88-11Amend & & 1988 & $11 / 11 / 1988$ & $01 / 02 / 1992$ & 3.2 & Y & GMDSS, date into force varied per ship type \\
\hline all & SOLAS88-Prot & & 1988 & $11 / 11 / 1988$ & $03 / 02 / 2000$ & 11.2 & $\mathrm{Y}$ & introduced new harmonized system of surveys and certification (HSSC) \\
\hline
\end{tabular}




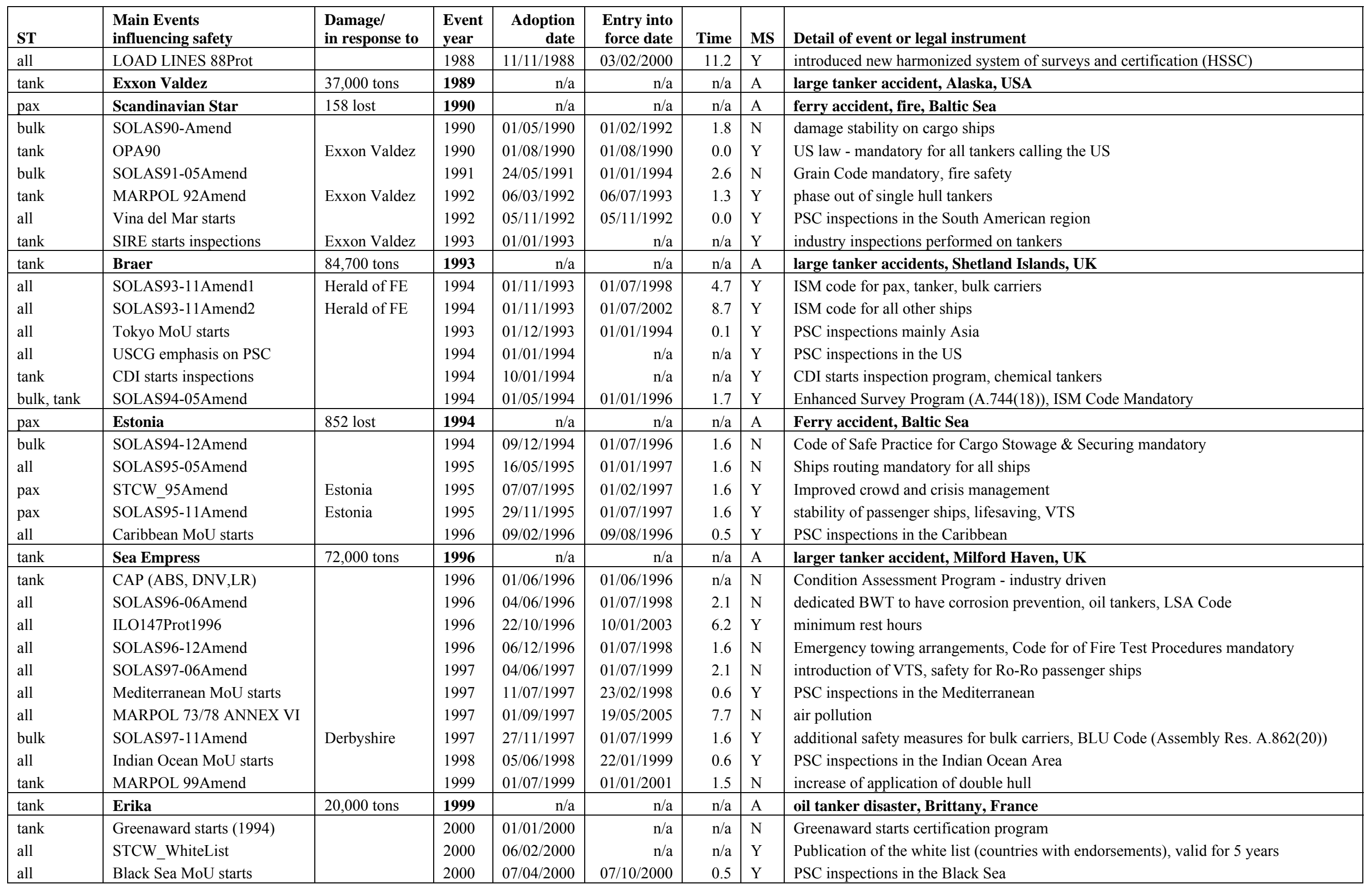




\begin{tabular}{|c|c|c|c|c|c|c|c|c|}
\hline ST & $\begin{array}{l}\text { Main Events } \\
\text { influencing safety }\end{array}$ & $\begin{array}{l}\text { Damage/ } \\
\text { in response to }\end{array}$ & $\begin{array}{l}\text { Event } \\
\text { year }\end{array}$ & $\begin{array}{r}\text { Adoption } \\
\text { date }\end{array}$ & $\begin{array}{l}\text { Entry into } \\
\text { force date }\end{array}$ & Time & MS & Detail of event or legal instrument \\
\hline all & SOLAS00Amend & & 2000 & $06 / 12 / 2000$ & $01 / 07 / 2002$ & 1.6 & $\mathrm{~N}$ & AIS, FSS Code, FTP Code \\
\hline tank & MARPOL 01Amend & Erika & 2001 & $27 / 04 / 2001$ & 01/09/2002 & 1.3 & $\mathrm{Y}$ & Condition Assessment Scheme, oil tankers \\
\hline bulk & Rightship starts vetting & & 2001 & $01 / 10 / 2001$ & $\mathrm{n} / \mathrm{a}$ & $\mathrm{n} / \mathrm{a}$ & $\mathrm{Y}$ & RightShip starts vetting inspection system, dry bulk \\
\hline bulk & Christoper & 27 lost & 2001 & $\mathrm{n} / \mathrm{a}$ & $\mathrm{n} / \mathrm{a}$ & $\mathrm{n} / \mathrm{a}$ & A & bulk carrier accident - forward flooding, similar to Derbyshire \\
\hline tank & EC Regulation 417/2002 & Erika & 2002 & $18 / 02 / 2002$ & $01 / 09 / 2002$ & 0.5 & $\mathrm{Y}$ & phasing out of single hull, category 1,2 and 3 tankers \\
\hline con & SOLAS02-05Amend & & 2002 & $24 / 05 / 2002$ & $01 / 01 / 2004$ & 1.6 & $\mathrm{~N}$ & IMDG mandatory \\
\hline pax & Joola & 1863 lost & 2002 & $\mathrm{n} / \mathrm{a}$ & $\mathrm{n} / \mathrm{a}$ & $\mathrm{n} / \mathrm{a}$ & $\mathrm{A}$ & ferry disaster, West Africa \\
\hline $\operatorname{tank}$ & Prestige & 77,000 tons & 2002 & $\mathrm{n} / \mathrm{a}$ & $\mathrm{n} / \mathrm{a}$ & $\mathrm{n} / \mathrm{a}$ & $\mathrm{A}$ & oil tanker disaster, Spain \\
\hline bulk & SOLAS02-12Amend & Derbyshire & 2002 & $12 / 12 / 2003$ & 01/07/2004 & 1.6 & $\mathrm{Y}$ & high level alarms, water ingress system (MSC Resolution 145(77)) \\
\hline $\operatorname{tank}$ & EC Regulation $1726 / 2003$ & Erika, Prestige & 2003 & $22 / 07 / 2003$ & $21 / 10 / 2003$ & 0.2 & $\mathrm{Y}$ & revised EU regulation 417/2002 - accelerated phase out \\
\hline tank & Tasman Spirit & 30,000 tons & 2003 & $\mathrm{n} / \mathrm{a}$ & $\mathrm{n} / \mathrm{a}$ & $\mathrm{n} / \mathrm{a}$ & A & oil tanker disaster, Pakistan \\
\hline $\operatorname{tank}$ & MARPOL 03Amend & Erika, Prestige & 2003 & $04 / 12 / 2003$ & $05 / 04 / 2005$ & 1.3 & $\mathrm{Y}$ & final phase out of $\mathrm{SH}$, carriage of heavy grade oil \\
\hline all & SOLAS04-05Amend & & 2004 & $01 / 05 / 2004$ & 01/07/2006 & 2.2 & $\mathrm{~N}$ & reduce accidents with lifeboats \\
\hline tank & MARPOL 04Amend & & 2004 & $01 / 10 / 2004$ & 01/01/2007 & 2.3 & $\mathrm{~N}$ & new categories for harmful substances \\
\hline bulk & SOLAS04-12Amend & & 2004 & $01 / 12 / 2004$ & 01/07/2006 & 1.6 & Y & new requirements related to double side skins, free fall lifeboat mandatory for bulk \\
\hline all & Voluntary MS Audit & & 2005 & $01 / 12 / 2005$ & $\mathrm{n} / \mathrm{a}$ & $\mathrm{n} / \mathrm{a}$ & $\mathrm{Y}$ & Voluntary MS Audit Scheme adopted (Assembly Resolution A974(24)) \\
\hline pax & Al Salam Boccachio 98 & 1000 lost & 2006 & $\mathrm{n} / \mathrm{a}$ & $\mathrm{n} / \mathrm{a}$ & $\mathrm{n} / \mathrm{a}$ & A & ferry accident, Red Sea \\
\hline pax & Star Princess & 1 lost & 2006 & $\mathrm{n} / \mathrm{a}$ & $\mathrm{n} / \mathrm{a}$ & $\mathrm{n} / \mathrm{a}$ & A & cruise ship accident - fire, coast of Jamaica \\
\hline pax & SOLAS06-12Amend & & 2006 & $01 / 12 / 2006$ & $01 / 07 / 2008$ & 1.6 & $\mathrm{~N}$ & amended fire protection requirements \\
\hline all & Maritime Labor Conv. 2006 & & 2006 & $07 / 02 / 2006$ & Not in force & $\mathrm{n} / \mathrm{a}$ & $\mathrm{Y}$ & revised ILO Maritime Conventions, possible entry into force dates: 2010/11 \\
\hline
\end{tabular}

Notes:

ST = ship types as follows: all, bulk (bulk carriers), pax (passenger vessels), tank (tankers)

Time = measures time between adoption and enforcement of legal instrument

$\mathrm{MS}=$ milestones: $Y=y e s, N=$ no, $A=$ accident 


\section{Appendix 2: Summary of variables used in models}

\begin{tabular}{|c|c|c|}
\hline Ship particulars & Description & Remark \\
\hline TOTALSHIPS & total ships used sometimes for the calculation of the dependent var. & sum/month \\
\hline AGE_MEAN & mean age all ships & mean/month \\
\hline AGE_DB & mean age dry bulk & mean/month \\
\hline AGE_GC & mean age general cargo & mean/month \\
\hline AGE_PA & mean age passenger ships & mean/month \\
\hline AGE_TA & mean age tanker & mean/month \\
\hline AGE_CON & mean age container vessels & mean/month \\
\hline GRT_MEAN & mean GT all ships & mean/month \\
\hline GRT_DB & mean GT dry bulk & mean/month \\
\hline GRT_GC & mean GT general cargo & mean/month \\
\hline GRT_CON & mean GT container vessels & mean/month \\
\hline GRT_PA & mean GT passenger & mean/month \\
\hline GRT_TA & mean GT tanker & mean/month \\
\hline Ratification variables & Description & Remark \\
\hline CR_COL72 & number countries ratified COLREG & sum $/$ month \\
\hline CR_ILO47 & number countries ratified ILO47 Convention & sum $/$ month \\
\hline CR_ILO96 & number countries ratified ILO96 Protocol & sum/month \\
\hline CR_LOA66 & number countries ratified Load Line 66 Convention & sum $/$ month \\
\hline CR_LOA88 & number countries ratified Load Line 88 Protocol & sum $/$ month \\
\hline CR_MARA1 & number countries ratified MARPOL Annex I - oil & sum $/$ month \\
\hline CR_MARA2 & number countries ratified MARPOL Annex II - NLS & sum $/$ month \\
\hline CR_MARA3 & number countries ratified MARPOL Annex III - IMDG & sum $/$ month \\
\hline CR_SOL74 & number countries ratified SOLAS 74 Convention & sum $/$ month \\
\hline CR_SOL78 & number countries ratified SOLAS 78 Protocol & sum $/$ month \\
\hline CR_SOL88 & number countries ratified SOLAS 88 Protocol & sum $/$ month \\
\hline CR_STW8 & number countries ratified STCW Convention & sum $/$ month \\
\hline CR_TON69 & number countries ratified Tonnage Convention & sum $/$ month \\
\hline $\begin{array}{l}\text { Entry into force of legal } \\
\text { instrum. and amendments }\end{array}$ & Description & Remark \\
\hline IN_SOL74C & SOLAS 1974 convention & indicator $0 / 1$ \\
\hline IN_SOL78P & Protocol of 1978 to SOLAS & indicator $0 / 1$ \\
\hline IN_SOL88P & Protocol of 1988 to SOLAS & indicator $0 / 1$ \\
\hline IN_SOL81A & SOLAS amendment 1981 & indicator $0 / 1$ \\
\hline IN_SOL88A & SOLAS amendment 1988 & indicator $0 / 1$ \\
\hline IN_SOL93A1 & SOLAS amendment 1993-1 (tanker, dry bulk, passenger) & indicator $0 / 1$ \\
\hline IN_SOL93A2 & SOLAS amendment 1993-2 (container, general cargo, other ST) & indicator $0 / 1$ \\
\hline IN_SOL94A & SOLAS amendment 1994 & indicator $0 / 1$ \\
\hline IN_SOL95A & SOLAS amendment 1995 & indicator $0 / 1$ \\
\hline IN_SOL96A & SOLAS amendment 1996 (FSA Code and Fire Testing) & Indicator $0 / 1$ \\
\hline IN_SOL97A & SOLAS amendment 1997 & indicator $0 / 1$ \\
\hline IN_SOL02A & SOLAS amendment 2002 & indicator $0 / 1$ \\
\hline IN_SOL04A & SOLAS amendment 2004 & indicator $0 / 1$ \\
\hline IN_COL72C & COLREG convention 1972 & indicator $0 / 1$ \\
\hline IN_LL66C & Load Line convention 1966 & indicator $0 / 1$ \\
\hline IN_LL88P & Protocol of 1988 to Load line & indicator $0 / 1$ \\
\hline IN_STW78C & STCW Convention 1978 & indicator $0 / 1$ \\
\hline IN_STW95A & STCW amendment 1995 & indicator $0 / 1$ \\
\hline IN_STWWL & STCW While List & indicator $0 / 1$ \\
\hline IN_SAR79C & SAR convention 1979 & indicator $0 / 1$ \\
\hline IN_MARA1 & MARPOL convention 73/78 Annex I & indicator $0 / 1$ \\
\hline IN_MARA2 & MARPOL convention 73/78 Annex II & indicator $0 / 1$ \\
\hline IN_MARA3 & MARPOL convention 73/78 Annex III & indicator $0 / 1$ \\
\hline IN_MAR92A & MARPOL 92 amendment - double hull requirements for tankers & indicator $0 / 1$ \\
\hline
\end{tabular}




\begin{tabular}{|c|c|c|}
\hline Entry into force cont. & Description & Remark \\
\hline IN_MAR99A & MARPOL 99 amendment - increased double hull requirement & Indicator $0 / 1$ \\
\hline IN_MAR01A & MARPOL 01 amendment - CAS for tankers & indicator $0 / 1$ \\
\hline IN_MAR03A & MARPOL 03 amendment - final phase of single hull tankers & indicator $0 / 1$ \\
\hline IN_ILO76C & International Labor Convention 147, 1976 & indicator $0 / 1$ \\
\hline IN_ILO96P & Protocol for ILO Convention 147 & indicator $0 / 1$ \\
\hline IN_IBC & IBC Code mandatory & Indicator $0 / 1$ \\
\hline IN_OPA90 & Oil Pollution Act 90 - mandatory aw for tankers calling the US & indicator $0 / 1$ \\
\hline $\begin{array}{l}\text { Time between adoption } \\
\text { and entry into force }\end{array}$ & Description & Remark \\
\hline AD_SOL81A & time between adoption and entry into force, all ships & dummy $0 / 1$ \\
\hline AD_SOL88A & time between adoption and entry into force, all ships & dummy $0 / 1$ \\
\hline AD_SOL93A1 & time between adoption and entry into force, all ships & dummy $0 / 1$ \\
\hline AD_SOL93A2 & time between adoption and entry into force, all ships & dummy $0 / 1$ \\
\hline AD_SOL95A & time between adoption and entry into force, passenger ships & dummy $0 / 1$ \\
\hline AD_SOL97A & time between adoption and entry into force, bulk & dummy $0 / 1$ \\
\hline AD_SOL02A & time between adoption and entry into force, bulk & dummy $0 / 1$ \\
\hline AD_SOL04A & time between adoption and entry into force, bulk & dummy $0 / 1$ \\
\hline AD_ILO96P & time between adoption and entry into force, all ships & dummy $0 / 1$ \\
\hline AD_MAR92A & time between adoption and entry into force, tankers & dummy $0 / 1$ \\
\hline AD_MAR99A & time between adoption and entry into force, tankers & dummy $0 / 1$ \\
\hline AD_MAR01A & time between adoption and entry into force, tankers & dummy $0 / 1$ \\
\hline AD_MAR03A & time between adoption and entry into force, tankers & dummy $0 / 1$ \\
\hline AD_STW95A & time between adoption and entry into force, all ships & dummy $0 / 1$ \\
\hline Inspection variables & Description & Remark \\
\hline IND_PMOU & PSC inspections starts - covers all other regimes that follow & indicator $0 / 1$ \\
\hline IND_CDI & industry inspections (tankers) & indicator $0 / 1$ \\
\hline IND_RS & industry inspections (bulk carriers) & indicator $0 / 1$ \\
\hline IND_SIRE & industry inspections (tankers) & indicator $0 / 1$ \\
\hline DET_ALL & Detentions - all port state control inspections, all ships & sum/month \\
\hline DET_DB & detentions - dry bulk carriers & sum/month \\
\hline DET_TA & detentions - tankers & sum $/$ month \\
\hline DET_PA & detentions - passenger ships & sum $/$ month \\
\hline DET_GC & detentions - general cargo vessels & sum/month \\
\hline DET_CON & detentions - container vessels & sum/month \\
\hline Seasonal dummies & Description & Remark \\
\hline SEAS01 & season dummy January (used as reference) & dummy $0 / 1$ \\
\hline SEAS02 & season dummy February & dummy $0 / 1$ \\
\hline SEAS03 & season dummy March & dummy $0 / 1$ \\
\hline SEAS04 & season dummy April & dummy $0 / 1$ \\
\hline SEAS05 & season dummy May & dummy $0 / 1$ \\
\hline SEAS06 & season dummy June & dummy $0 / 1$ \\
\hline SEAS07 & season dummy July & dummy $0 / 1$ \\
\hline SEAS08 & season dummy August & dummy $0 / 1$ \\
\hline SEAS09 & season dummy September & dummy $0 / 1$ \\
\hline SEAS10 & season dummy October & dummy $0 / 1$ \\
\hline SEAS11 & season dummy November & dummy $0 / 1$ \\
\hline SEAS12 & season dummy December & dummy $0 / 1$ \\
\hline Ship economic cycles & Description & Remark \\
\hline EARN_CLARKINDEX & average earnings per months for all ships & mean/month \\
\hline EARN_BULK & average earnings per months for bulk carriers & mean/month \\
\hline EARN_CONT & Average earnings per months for container vessels & mean/month \\
\hline EARN_TANK & average earnings per months for tanker & mean/month \\
\hline
\end{tabular}

